\title{
AN ANALYTICAL STUDY OF EGYPTIAN ORANGE EXPORTS MARKETS FROM THE GROUP OF BRICS COUNTRIES
}

\author{
MOSTAFA ELGOHARY, RANIA TOLBA and MONIRA ELNAGAR
}

Agric. Econ. Res. Instit., ARC, Dokki, Giza, Egypt

(Manuscript received 2 nd February 2016)

\begin{abstract}
$\mathrm{T}$ he problem of the research is that, while the Egyptian orange exports occupies a special position in some countries in the group BRICS countries markets, but to maintain these markets or try to increase orange exports to them may face numerous obstacles or difficulties, especially in light of the signing and activating the setting up of the agreement BRICS, especially since some of the COMESA countries are producing countries and major exporter of oranges, and then this paper aims to examine the competitive conditions for exports of Egyptian oranges markets group BRICS countries, so that some of the proposals that help to maintain the presence of Egyptian oranges develop and raise the competitiveness of the stability and increase Egyptian exports of oranges to those markets. In light of the findings of the research, it can be recommended as follows: -
\end{abstract}

- Work on maintaining the current markets and the study of the causes of nonexistence of Egyptian oranges in the rest of the assembly markets and how to overcome obstacles to the entry and the presence of Egyptian oranges in light of the increasing growth in demand for oranges in these markets and, through: -

- the ability to raise Alantajph Exporters orange and the preservation of the status and the presence of Egyptian oranges in the Russian market and applying appropriate marketing strategy in light of the significant decline in the imports of the market during the last period.

- concern for the signing of a joint agreement between the Development Association and the development of horticultural crops and Export Council for Agricultural Crops with CAWA Chinese Foundation exports, which includes more than 300 importer and trader specialized Chinese sentence in agricultural crops and account for $80 \%$ of the agricultural products market in China, which promotes the export volumes large orange in all its forms to the Chinese market.

- To work on activating agreement Mercosur signed between Egypt and Brazil as an important tool to activate bilateral trade movement and increase the force of Egyptian goods and products to the markets of the Latin American continent rate instruments, with the need to improve the transportation system logistics between the two countries would contribute to strengthening trade relations between the two countries, and through the launch of regular lines for maritime transport between the two sides, with due attention to studying the possibilities of Egyptian oranges registered with the Ministry of Agriculture, Brazil Ki Egypt can export markets for the Brazilian. 


\title{
دراسة تحليلية لصادرات البرتقال المصرى بأسواق دول مجموعة البريكس
}

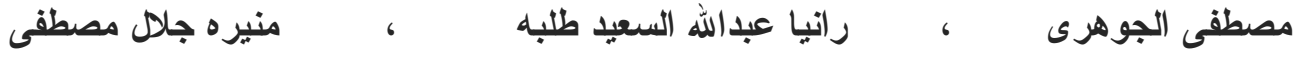 \\ معهُ بحوث الاقتصاد الزراعي - مركز البحوث الزراعية - الدقى - الجبزة
}

\section{الملخص}

تعتبر دول مجموعة دول البريكس من أكبر شركاء مصر التجاريين حيث يأتى التجمع فـى

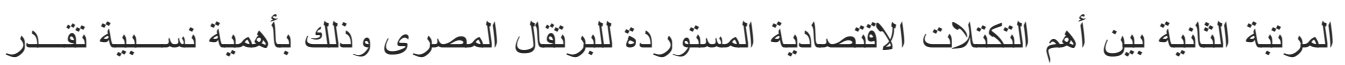

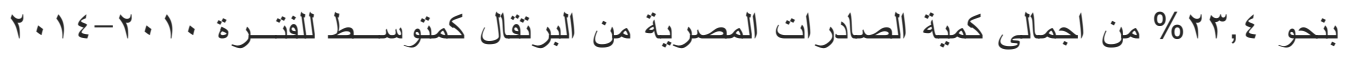

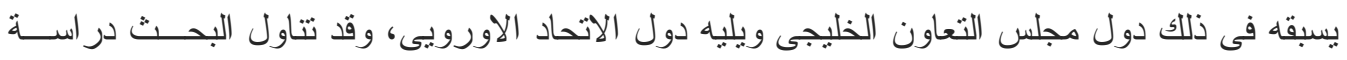

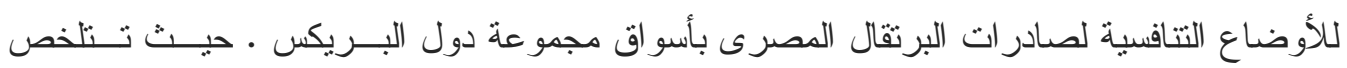

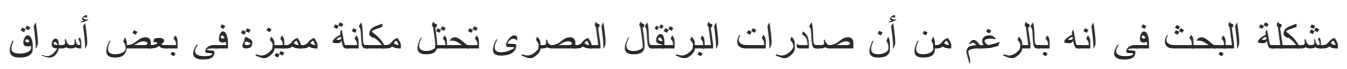

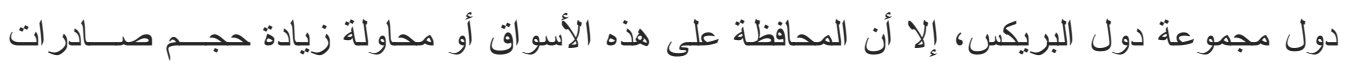

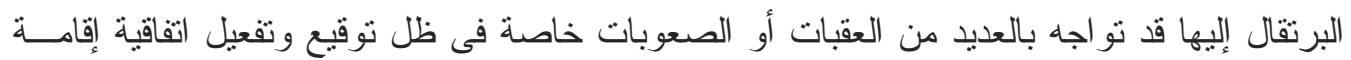

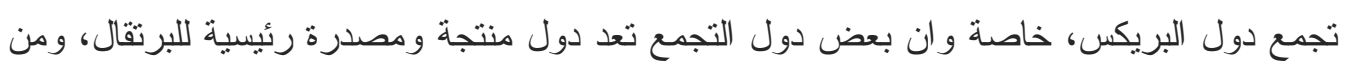

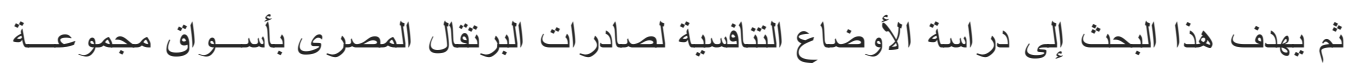

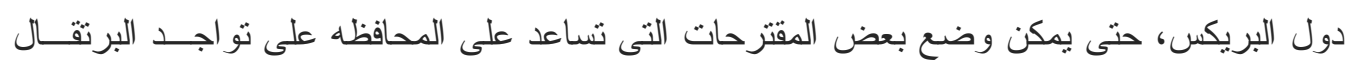
المصرى ورفع قدرته النتافسية في تلك الأسو اق.

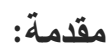

يحتل البرتقال المرتبة الأولى بين حاصلات الفاكهة فى مصر إذ بلغت المساحة المنزرعــة

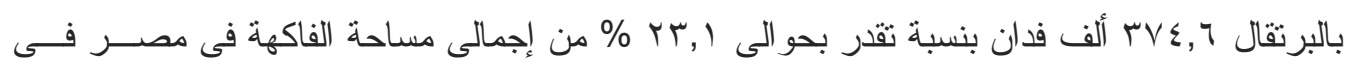

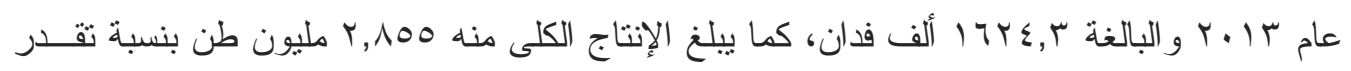

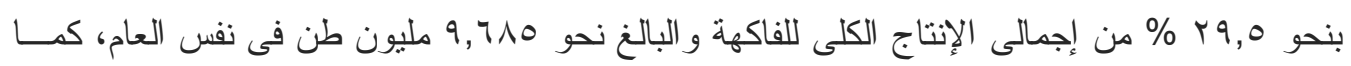

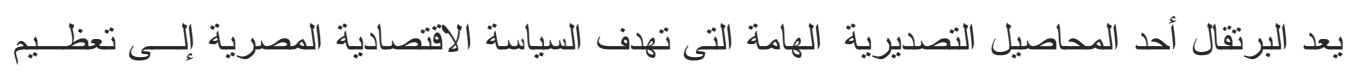

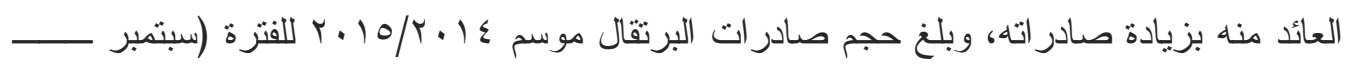

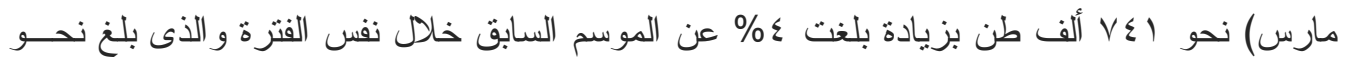

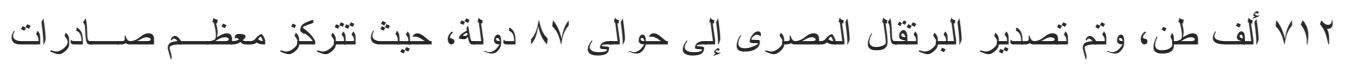

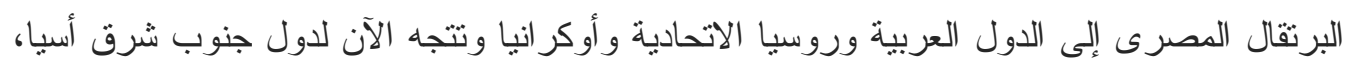

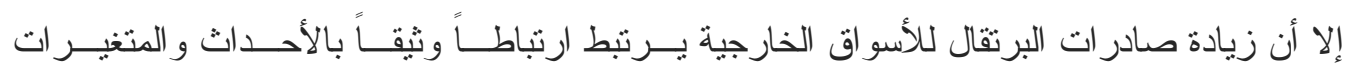

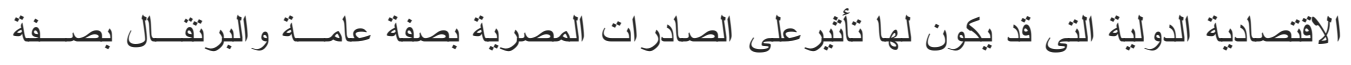

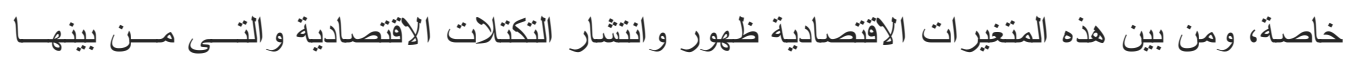
تجمع دول البريكس. 
مجموعة »البريكس" هي تكتل اقتصادي نم تأسيسه والإعلان عن قيامه عام ^ ... ويضم خمس دول هم روسيا الاتحادية و الصين و الهند و البرازيل وجنوب أفريقيا، وهى مجموعة الدول ذات

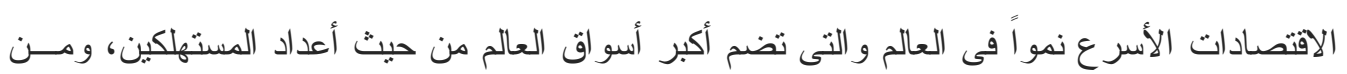
المتوقع مع استمر ار ارتفاع متوسط دخل الفرد و اقتر ابه من المستويات العالمية، أن تصبح مجموعــة "بريكس" أكبر الأسو اق الاستهلاكية، و المصطلح بريكس هو اختصـار اللحروف الأولى مـن أســماء الدول الخمس الأعضاء باللغة الإنجليزية هBRICS».

وتعتبر دول مجموعة دول البريكس من أكبر شركاء مصر التجاريين حيث يأتى التجمع فى

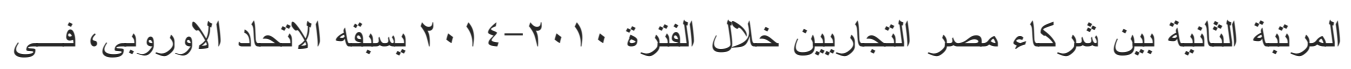
حين يلى تكتل البريكس فى الاهمية كل من مجلس التعاون الخليجى، تجمع الكوميسا ثم تكتل النافتــا،

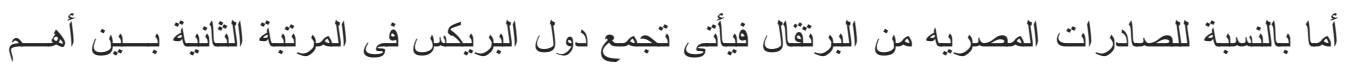
التكتلات الاقتصادية المستوردة للبرتقال المصرى وذلك بأهمية نسبية تقدر بنحو ع,r؟\% من اجمالى

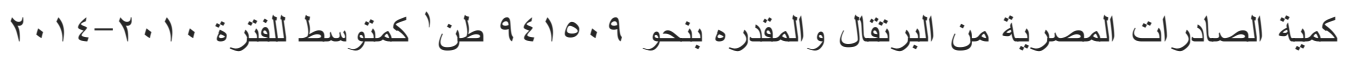
يسبقه فى ذلك دول مجلس التعاون الخليجى ويليه دول الاتحاد الاوروبى، وسوف يتتاول هذا البحــث در اسة تحليلية للأوضاع التتافسية لصادر ات البرتقال المصرى بأسواق مجموعة دول البريكس. المشكلة و الهرف البحثى: يعتبر البرتقال من أهم محاصيل الفاكهة التصديرية فى مصر ، وبالرغم مــن أن صــادر ات البرتقال المصرى تحتل مكانة مميزة فى بعض أسواق دول مجموعة دول البريكس، إلا أن المحافظة على هذه الأسو اق أو محاولة زيادة حجم صادر ات البرتقال إليها قد نو اجه بالعديد مــن العقبـات أو الصعوبات خاصة فى ظل توقيع وتفعيل اتفاقية إقامة تجمع دول البريكس وما يعنيه ذلك مسن مــنح مز ايا تفضيلية لدول التجمع فى تجارتها البينية وبعضها دول منتجة ومصدرة رئيسية للبرتقال، الأمر الذى قد يؤدى إلى زيادة حدة المنافسة التى تواجهها الصادر ات المصــرية مــن البرتقــال وزيــادة صعوبات تو اجد أو فتح أسو اق جديده للبرتقال المصرى بدول مجموعة دول البريكس . ويهدف البحث إلى التعرف على الوضع الر اهن لصـادرات البرتقال المصرى داخل اســـواق دول مجموعة دول البريكس ودر اسة الأوضاع التتافسية للبرتقال المصرى داخل أسواق دول التجمع، وكذلك در اسة هيكل التجارة الخارجية للبرتقال لدول مجموعة دول البريكس لمعرفة الميز ان التجارى 
الكمى للبرتقال وبيان العجز أو الفائض من هذا المحصول، إلى جانب التعرف على الآثار المتوقعـة للتجارة البينية بين دول التجمع بعد توقيع وتفعيل اتقاقية إقامة تجمع دول البريكس وما يعنيه ذلك من منح مز ايا تقضيلية لدول التجمع فى تجارتها البينية على صادرات البرتقال المصرى لدول التجمــع، حتى يمكن وضع بعض المقترحات التى تساعد على المحافظه على نو اجد البرتقال المصرى بأسواق دول التجمع وكيفية الاستفادة من العلاقات المميزه بين مصر وهذه الدول فى رفع القــدرة التتافسـية لاستقر ار وزيادة الصادر ات المصرية من البرتقال لتلك الأسواق • الطريقة البحثية ومصادر البيانات:

اعتمد البحث على أسلوب التحليل الوصفى والكمى بالإضافة إلى استخدام بعض المؤشرات و النماذج الرياضية التى تؤثر على المركز التتافسى لصادرات البرتقال المصرى و التى تساعد علـى تحقيق الهدف من البحث ومن بينها تحليل النصيب السوقى، التتافسية السعرية، قوة التصدير وكــللك النصيب السوقى لصادر ات برثقال للدول الكتنافسه داخل أسو اق دول مجموعة دول البــريكس، إلـى جانب در اسة موسمية واردات البرنقال بأسو اق دول مجموعة دول البريكس، وقد اعتمد البحث علـى البيانات المنشوره وغير المنشورة و التى تصدر ها الجهات المعنية ذات الصلة بموضوع البحث مثـلـل الجهاز المركزى للتعبئة العامة و الإحصاء، قاعدة بيانات منظمة الأغذية و الزر اعــة، قاعــدة بيانــات مركز التجارة العالمى التابع للأمم المتحدة.

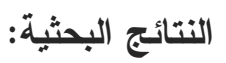

تطور كمية واردات أسواق دول مجموعة دول البريكس من البرتقال المصرى وأهميتها النسبية: تشير بيانات الجدول (1) إلى تطور كمية واردات أسواق دول مجموعة دول البريكس مسن

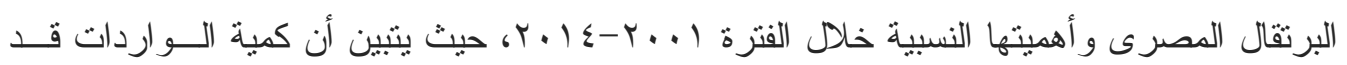

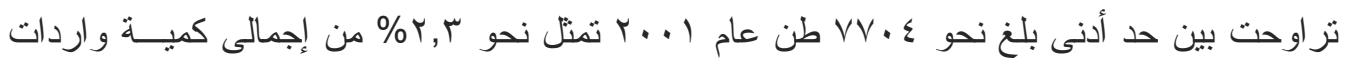

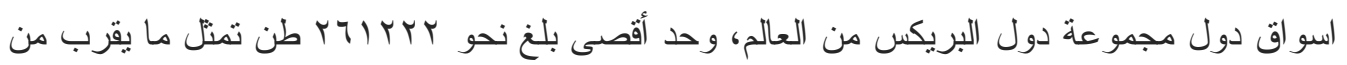

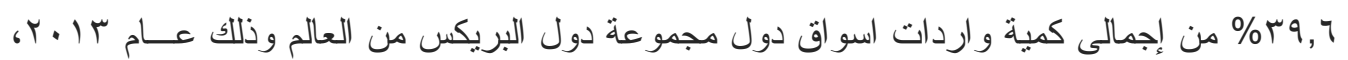

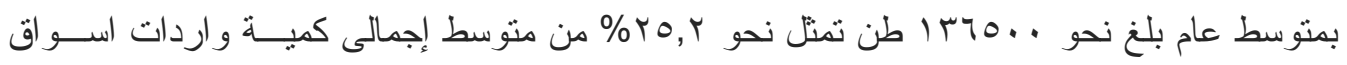

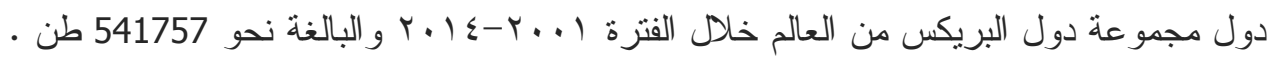

جدول ( ) : تطور كمية واردات أسواق دول مجموعة دول البريكس بالطن

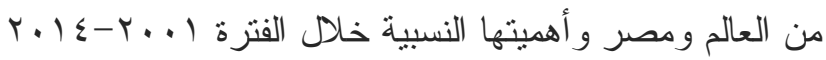




\begin{tabular}{|c|c|c|c|c|}
\hline \multicolumn{4}{|c|}{ واردات دول مجموعة دول البريكس } & \multirow{2}{*}{ 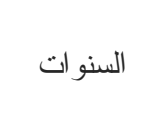 } \\
\hline$\%$ & من مصر & $\%$ & 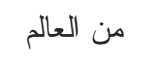 & \\
\hline 2.3 & 7704 & 7.0 & 336640 & 2001 \\
\hline 9.9 & 41059 & 8.4 & 414163 & 2002 \\
\hline 16.1 & 76222 & 9.1 & 473145 & 2003 \\
\hline 24.3 & 110015 & 8.5 & 451934 & 2004 \\
\hline 19.9 & 88685 & 8.3 & 445586 & 2005 \\
\hline 18.4 & 108955 & 10.6 & 591232 & 2006 \\
\hline 20.5 & 110170 & 8.0 & 537549 & 2007 \\
\hline 23.6 & 135370 & 9.7 & 572886 & 2008 \\
\hline 24.8 & 129845 & 8.6 & 523087 & 2009 \\
\hline 25.4 & 151264 & 9.2 & 596451 & 2010 \\
\hline 31.5 & 222577 & 10.8 & 705580 & 2011 \\
\hline 33.3 & 213160 & 9.8 & 640064 & 2012 \\
\hline 39.6 & 261222 & 9.5 & 660255 & 2013 \\
\hline 40.1 & 254755 & 9.7 & 636024 & 2014 \\
\hline$r 0, r$ & 136500 & 9,1 & 541757 & متوسط الفترة \\
\hline
\end{tabular}

المصدر : جمعت وحسبث من : قاعدة بيانات مركز التجارة العالمى WWW.comtrade.com

وتتشير معادلة الاتجاه الزمنى العام لتطور كمية واردات أسواق دول مجموعة دول البريكس

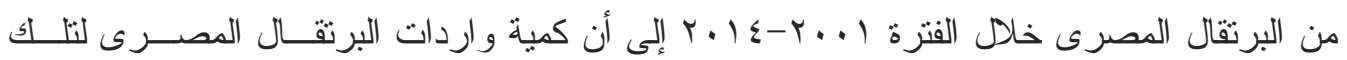

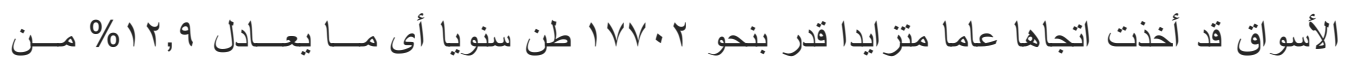
متوسط إجمالى كمية واردات أسو اق دول مجموعة دول البريكس من البرتقال المصرى خلال فتــرة الدر اسة و البالغة نحو ..07 ا طن، وقد ثبتت معنوية هذه الزيادة إحصائيا.

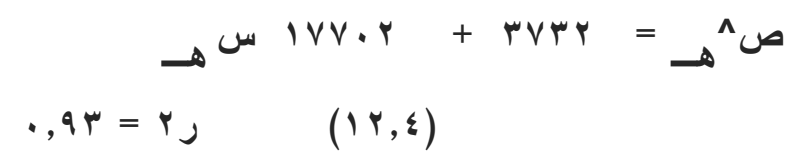

حيث : ص^هـ....القيمة التقديرية لكمية واردات أسو اق دول مجموعة دول البريكس من البرتقــال المصرى بالطن. القيمة بين الأقو ساس هى قيمة " ت "

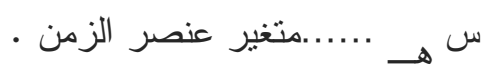

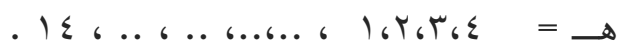

التوزيع الجغرافى لصادرات البرتقال المصرى واهميتها النسبية لأسواق دول مجموعة دول البريكس:

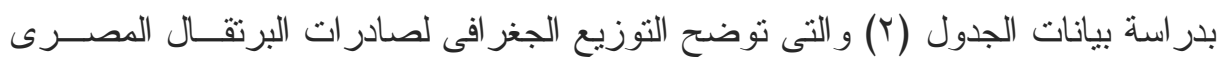

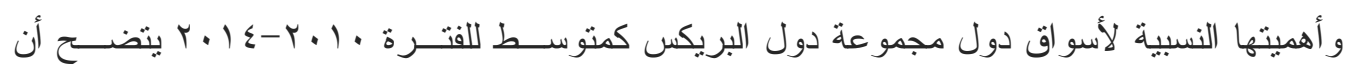

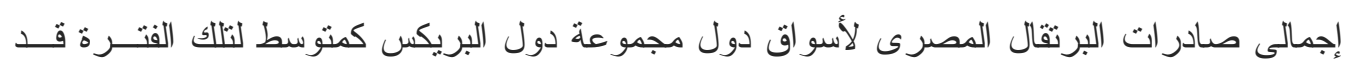

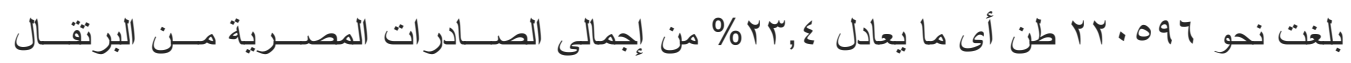

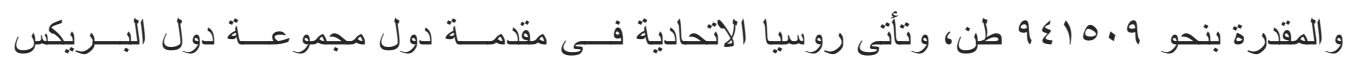




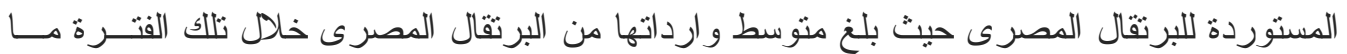

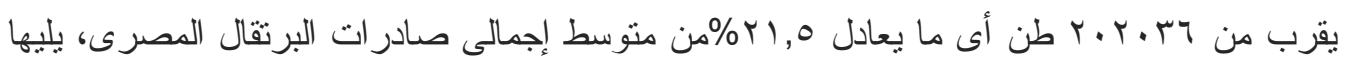

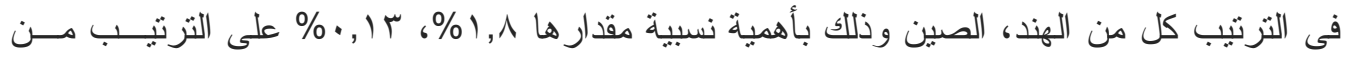
متوسط إجمالى صادر ات البرتقال المصرى •

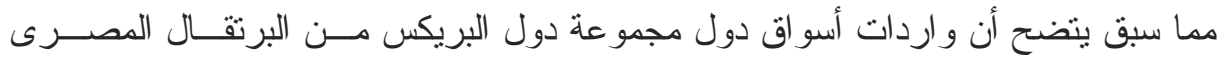
تتركز بصفة رئيسية فى السوق الروسى و الذى يشكل نحو 7 , 19\% من حجم صادر ات مصــر مسنـ البرتقال لدول مجموعة دول البريكس، الأمر الذى يستلزم العمل على المحافظة على الأسواق الحالية

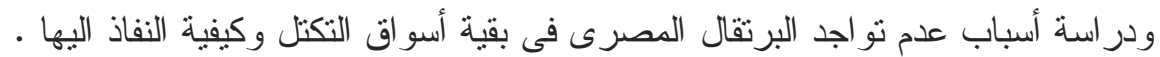
جدول (Y) : التوزيع الجغر افى لصادر ات البرتقال المصرى و أهميتها النسبية لأسو اق دول مجموعة

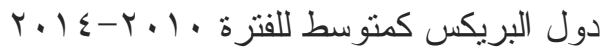

\begin{tabular}{|c|c|c|}
\hline \% من إجمالى صادرات البرتقال المصرى & الواردات من مصر بالطن & دول تحمع البريكس \\
\hline 21.5 & Y.r.M & روسيا الاتحادية \\
\hline 0.13 & $|r| \Lambda, \Lambda$ & الصين \\
\hline 1.8 & IVrr., A & الهند \\
\hline 00 & 9,7 & جنوب افريقيا \\
\hline-- & -- & البر ازيل \\
\hline 23.4 & 220595.6 & إجمالى دول مجموعة دول البريكس \\
\hline \multicolumn{2}{|l|}{941509.4} & إجمالى صادرات البرتقال المصرى \\
\hline
\end{tabular}

المصدر : جمعت وحسبت من : قاعدة بيانات مركز التجارة العالمى Www.comtrade.com

النصيب السوقى للصادرات المصرية من البرتقال فى أسواق دول مجموعة دول البريكس : يعتبر النصيب السوقى أحد مؤشرات التتافسية، ذلك لأن النصيب السوقي فى حد ذاته يعتبر

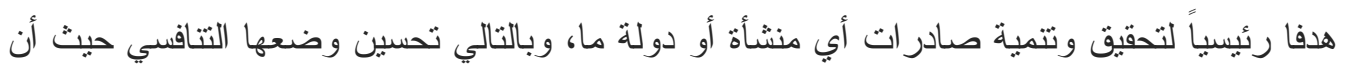
ارتفاعه يمثل أحد العو امل الرئيسية لعملية توسيع حجم المبيعات الخارجية لأي دولــة، وبـــللك فــان

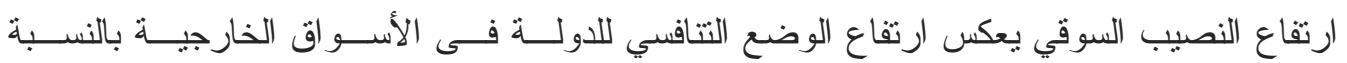
للمحصول المصدر ، ويتم حسابه بالمعادلة التالية:

\section{كمية صادرات الاولة لسوق معين من سلعة معينة}

$$
1 \ldots \times
$$$$
\text { النصيب السوقى }
$$

$$
\text { إجمالى كمية واردات السوق من تلك السلعة }
$$

بدر اسة بيانات الجدول (r) و الذى يوضح متوسط النصيب السوقى للصادر ات المصرية من

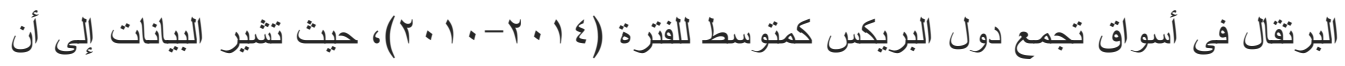

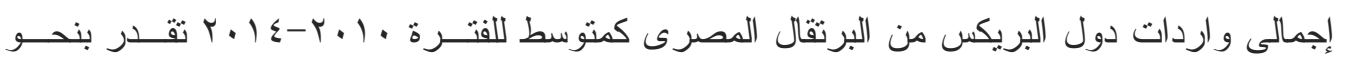

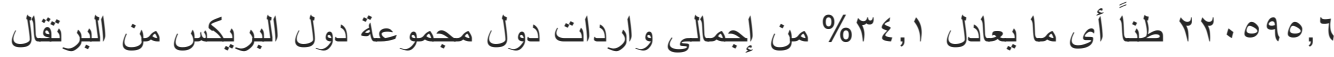

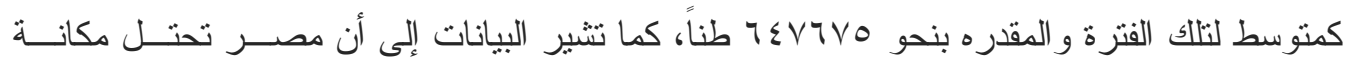
مميزة من حيث النصيب السوقى داخل كل من السوق الهندى وسوق روسيا الاتحاديــة حبــث بلـــن 


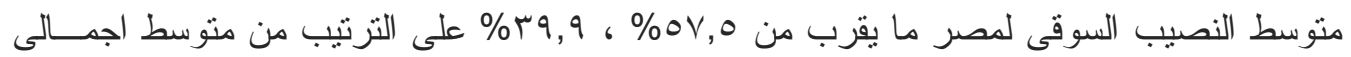
كمية واردات الهند وروسيا الاتحادية من البرتقال .

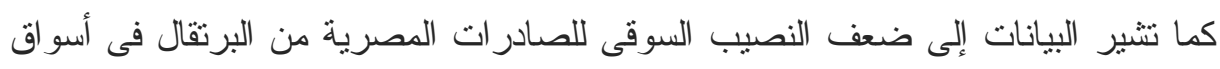

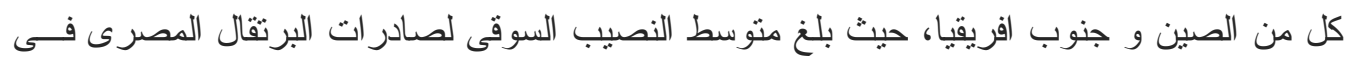

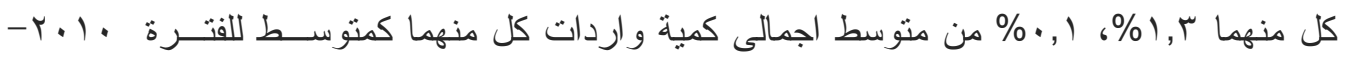

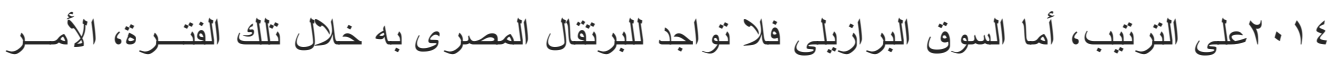

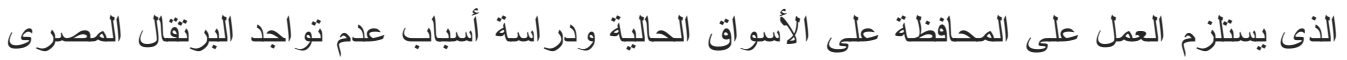

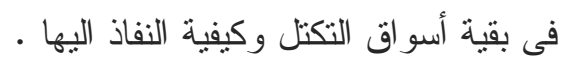
جدول (ץ): المتوسط السنوى للنصيب السوقي للبرتقال المصرى فيى أسواق دول مجموعة

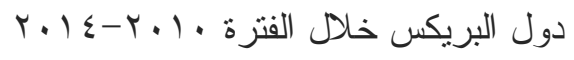

\begin{tabular}{|c|c|c|c|}
\hline \% النصيب السوقى & الواردات من مصر طن & إجمالى واردات السوق & دول تحمع البريكس \\
\hline$r 9,9$ & $r \cdot r \cdot r q, \varepsilon$ & 505718 & روسيا الاتحادية \\
\hline $1, r$ & $|r| \wedge, \wedge$ & 90855.8 & الصين \\
\hline$\Delta V, 0$ & IVRr., A & 30149.6 & الهند \\
\hline-- & -- & 12011.4 & البرازيل \\
\hline., 1 & 9,7 & 8940 & جنوب افريقبا \\
\hline$r \leqslant, 1$ & 220595.6 & 647675 & إجمالى دول مجموعة دول \\
\hline
\end{tabular}

مصادر نمو صادرات البرتقال المصرى لأسواق دول مجموعة دول البريكس :

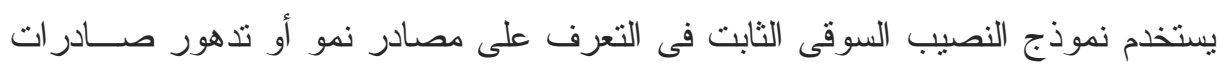
محصول ما إلى تكتل معين أو منطقة معينه، ويمكن من خلال هذا النموذج تحديد مقدار كل من أثــر

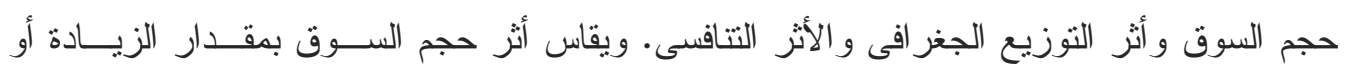

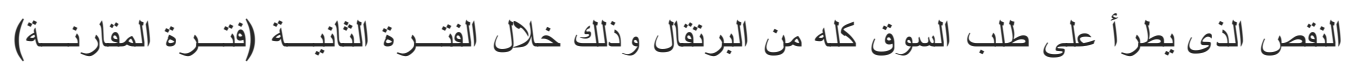

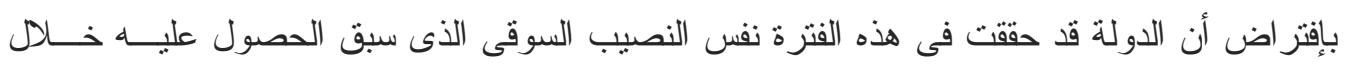

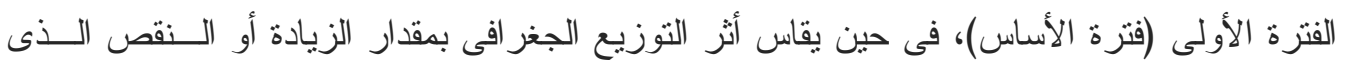

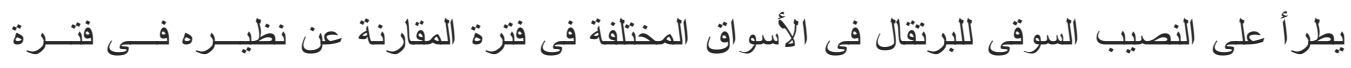

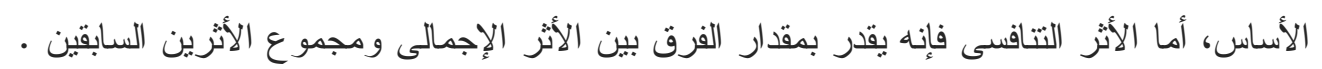

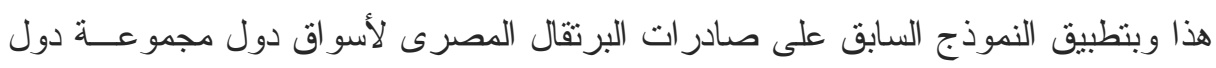

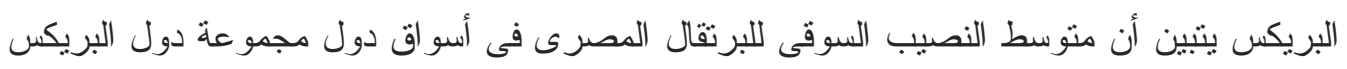

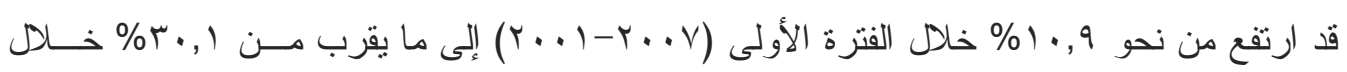

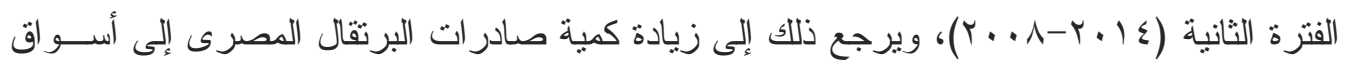

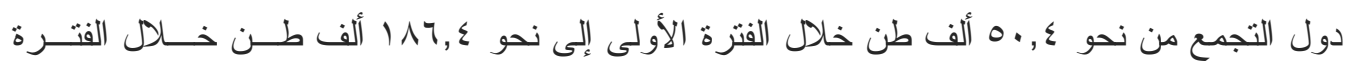




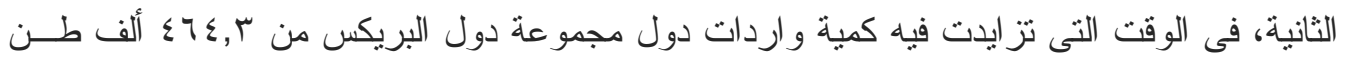

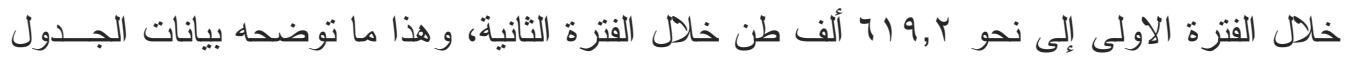

جدول (ع): الصادر ات الفرضية للبرثقال المصرى لأسو اق دول مجموعة دول البريكس

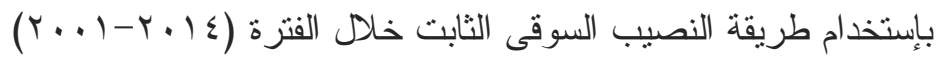

\begin{tabular}{|c|c|c|c|c|c|c|c|}
\hline \multirow{2}{*}{ الفرضيه } & \multicolumn{3}{|c|}{ 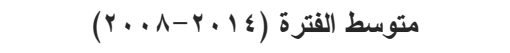 } & \multicolumn{3}{|c|}{ 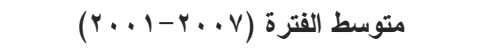 } & \multirow{2}{*}{ البريكس تجمع } \\
\hline & $\begin{array}{c}\text { \% } \\
\text { النصبب }\end{array}$ & صادر ات مصر & واردات السوق & $\begin{array}{c}\text { \% } \\
\text { النصبب }\end{array}$ & صصادرات & واردات السوق & \\
\hline 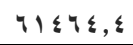 & 34.79 & 172672.4 & 496303.0 & 12.38 & 50093.0 & 404482.7 & روسيا \\
\hline r^q,q & 1.59 & 1318.3 & 82657.7 & 0.35 & 180.4 & 51452.1 & الصين \\
\hline$r \cdot 1, \varepsilon$ & 52.43 & 12403.3 & 23655.4 & 1.27 & 16.9 & 1323.0 & الهند \\
\hline$\Lambda r \Lambda, 1$ & 0.00 & 0.0 & 8978.9 & 9.22 & 127.0 & 1377.0 & البرازيل \\
\hline$r \varepsilon, \cdot$ & 0.58 & 44.1 & 7597.4 & 0.45 & 25.4 & 5686.4 & جنوب \\
\hline rrq1 & 30.11 & 186438.1 & 619192.4 & 10.86 & 50442.7 & 464321.3 & 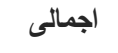 \\
\hline
\end{tabular}

المصدر : جمعت وحسبت من : قاعدة بيانات مركز التجارة العالمى www.comtrade.com

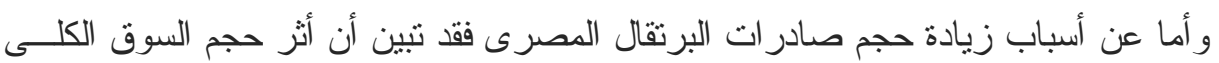

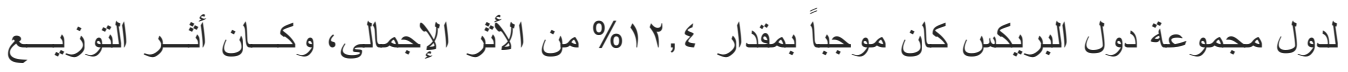

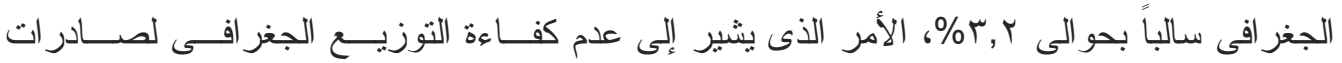

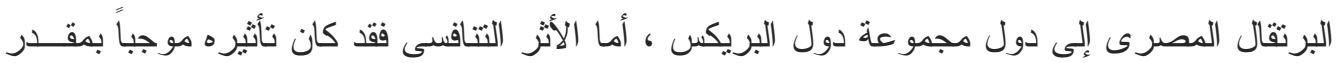

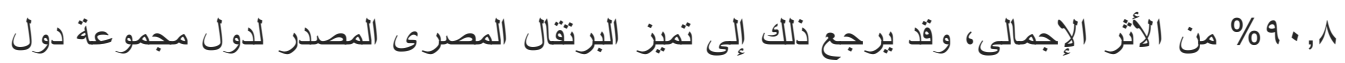

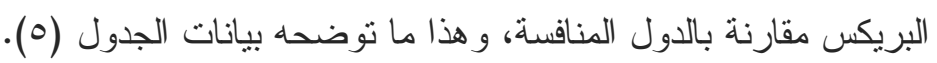
الميزان التجارى الكمى للبرتقال بدول مجموعة دول البريكس: بالنول

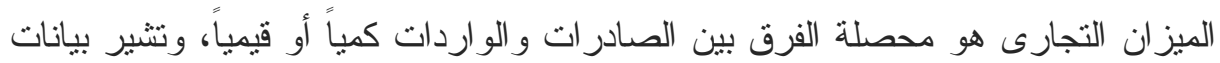
الجدول (7) إلى أن الميزان التجارى الكمى للبرتقال بدول مجموعة دول البريكس كمتوسط للفتــرة

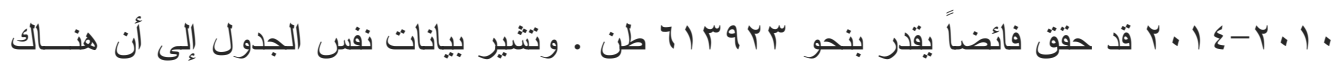

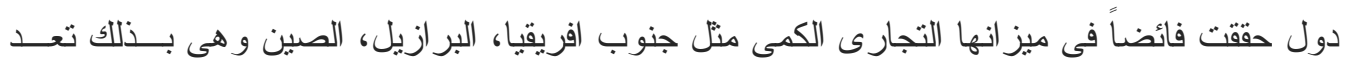

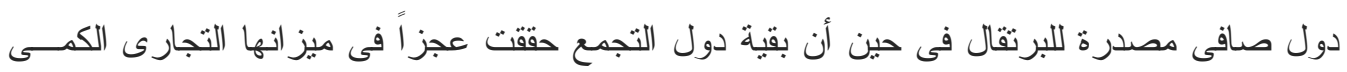

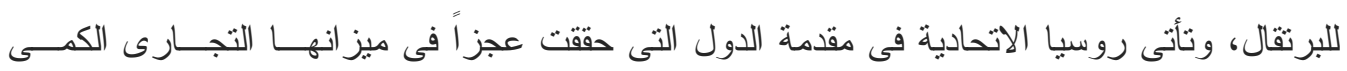

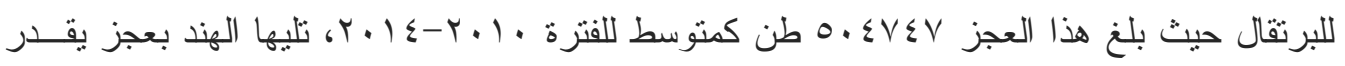

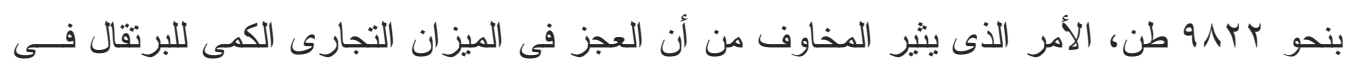

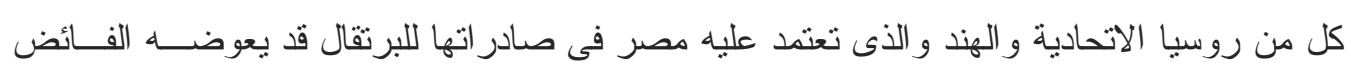

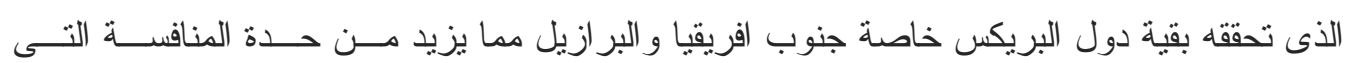

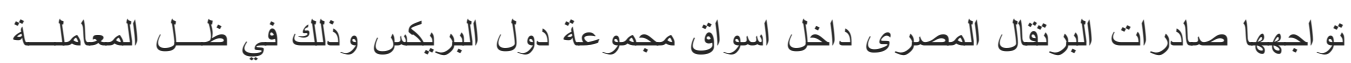
التفضيلية التي تحصل عليها دول التجمع بالضرورة. 
جدول (0) : تحليل النصبي السوقى الثابت لصادر ات البرتقال المصرى لدول مجموعة دول

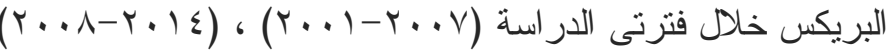

\begin{tabular}{|c|c|c|}
\hline 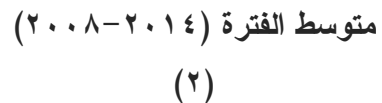 & 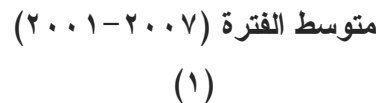 & الصادرات و الأنصبه الفعلية المصرية \\
\hline 619192.4 & 464321.3 & اجمالى و اردات دول التجمع (طن) \\
\hline 186438.1 & 50442.7 & صادرات مصر لدول التجمع (طن) \\
\hline 30.1 & 10.9 & النصيب السوقى لمصر \% \\
\hline
\end{tabular}

\begin{tabular}{|c|c|}
\hline 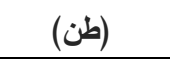 & الصادرات الفرضية المصرية \\
\hline 67244.3 & (أ) صادرات مصر الفرضية فى الفترة الثانية لو حافظت على نصيبها فى اسواق التجمع فى \\
\hline 62917.8 & (ب) صادرات مصر الفرضية فى الفترة الثانية لو حافظت على نصيبها السوقى فى كل سوق من \\
\hline
\end{tabular}

\begin{tabular}{|c|c|c|}
\hline$\%$ & طن & الأثز على الصادرات المصرية \\
\hline 100.0 & 135995.4 & الاثز الاجمالى ( ا-r ) \\
\hline 12.4 & 16801.6 & اثر نمو حجم السوق الكلى للتجمع ( أ-1 ) \\
\hline-3.2 & -4326.5 & اثر التوزيع الجغرافى للصادرات المصرية لدول التجمع ( ب-أ ) \\
\hline 90.8 & 123520.3 & الاثر التنافسى ( r-ب ) \\
\hline
\end{tabular}

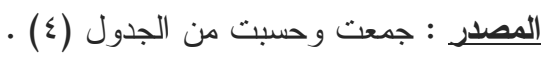

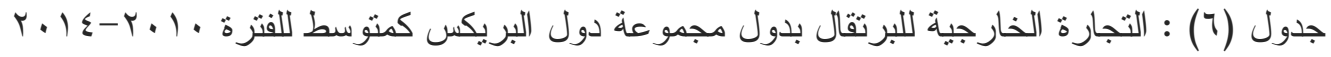

\begin{tabular}{|c|c|c|c|c|c|}
\hline الميزان الكمى & \multicolumn{2}{|c|}{ الو اردات } & \multicolumn{2}{|c|}{ الصادرات } & \multirow{2}{*}{ دول مجموعة دول البريكس } \\
\hline طن & $\%$ & طن & $\%$ & طن & \\
\hline $0 . \leqslant V \leqslant V(-)$ & $\vee \wedge, 1$ & $0.0 \mathrm{VI1}$ &., 1 & $9 \vee 1, r$ & روسيا الاتحادية \\
\hline 14550.2 & $1 \leqslant,$. & $9 \cdot 100,1$ & $\Lambda, \varepsilon$ & $1.0 \leqslant .7$ & الصين \\
\hline qAYr $(-)$ & $\varepsilon, V$ & $r .1 \leqslant 9,7$ & 1,7 & Y.rYV & الهند \\
\hline 15367.8 & $1, \wedge$ & $1 Y \cdot 11, \varepsilon$ & $r, r$ & rvrva,r & البر ازيل \\
\hline 1098574 & $1, \varepsilon$ & $\wedge 9 \leqslant$. & $\wedge \vee, \vee$ & $11 . v 01 \leqslant$ & جنوب افريقيا \\
\hline TIrart & $1 \ldots$ & 647674.8 & $1 \ldots$ & 1261597.4 & إجمالّى دول مجموعة دول \\
\hline
\end{tabular}

المصدر : جمعت وحسبت من : قاعدة بيانات مركز التجارة العالمى www.comtrade.com

الأنصبة السوقية للاول المتنافسة داخل أسواق دول مجموعة دول البريكس للبرتقال :-

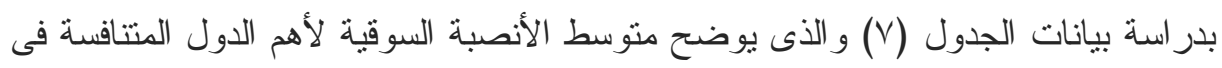

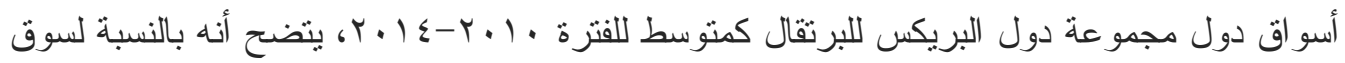

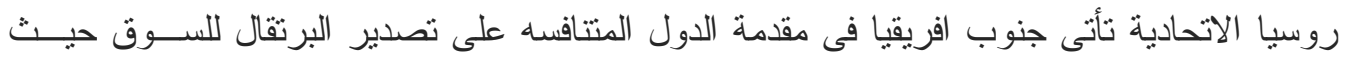

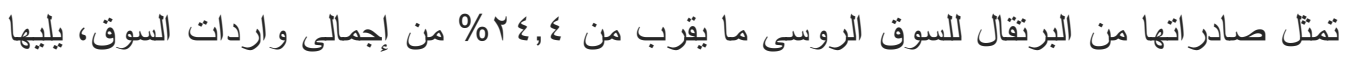

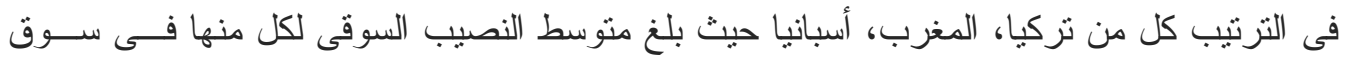

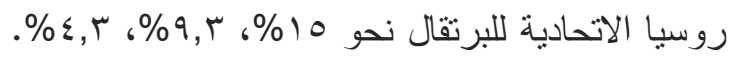


أما بالنسبة للسوق الصينى فتأتى أمريكا قى مقدمة الدول المتتافسه على تصــدير البرتقــال

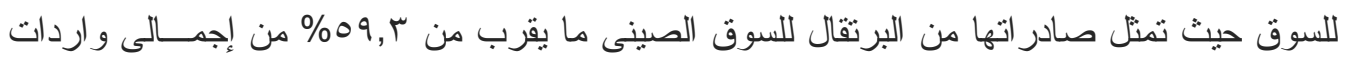

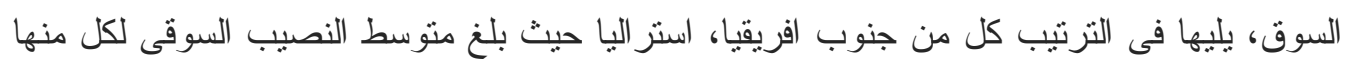

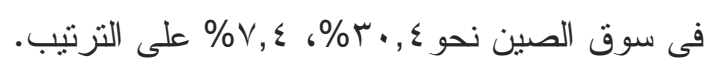

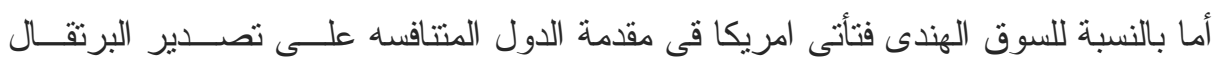

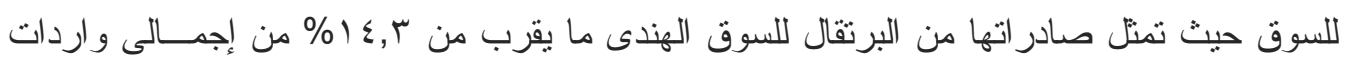

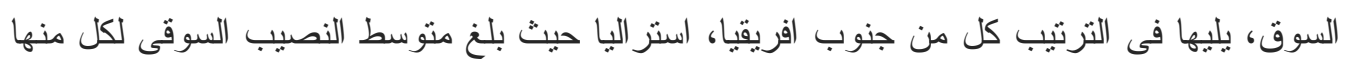

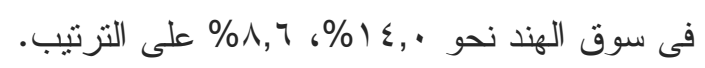

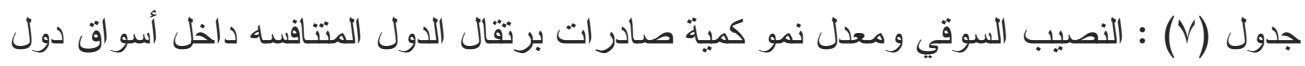
(\%)

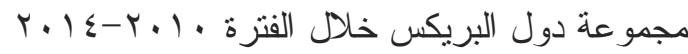

\begin{tabular}{|c|c|c|c|c|c|c|c|c|c|c|}
\hline \multicolumn{10}{|c|}{ أسواق دول مجموعة دول البريكس } & \multirow{4}{*}{ الاول المتنافسه } \\
\hline \multicolumn{2}{|c|}{ جنوب افريقيا } & \multicolumn{2}{|c|}{ 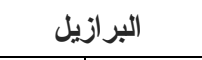 } & \multicolumn{2}{|c|}{ 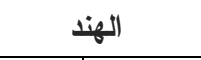 } & \multicolumn{2}{|c|}{ 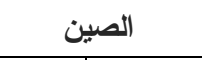 } & \multicolumn{2}{|c|}{ روسيا الاتحادية } & \\
\hline معدل & النصيب & معدل معل & النصيب & معدل & النصيب & معدل & النصيب & معل & النصيب & \\
\hline النمو & السوقى & النمو الن ال & السوقى & النمو & السوقى & النمو & السوقى & النمو & السوقى & \\
\hline-- & $\cdot, 1$ & -- & -- & $1 \leq$ & $\bullet \vee, \bullet$ & -- & $1, r$ & $\wedge$ & एq,q & 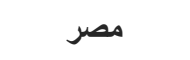 \\
\hline-- & -- & -- & -- & $r \cdot$ & $1 \leqslant$, & $0 \leqslant$ & $r \cdot, \varepsilon$ & • & $r \leq, \varepsilon$ & جنوب افريقيا \\
\hline-- & -- & -- & -- & -- & -- & -- & -- & $(0)$ & 10,0 & تركيا \\
\hline-- & -- & -- & -- & -- & -- & -- & -- & $\left(r_{0}\right)$ & $9, r$ & المغرب \\
\hline Vr & $r,$. & $\mu q$ & $\bullet \wedge, \varepsilon$ & -- & -- & -- & -- & 7 & $\varepsilon, \mu$ & اسباتيا \\
\hline-- & -- & -- & -- & -- & $r, 0$ & -- & -- & 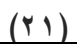 & $r, 1$ & الصين \\
\hline-- & -- & -- & -- & $(\leqslant v)$ & $1 \varepsilon, \mu$ & $(\mu \cdot)$ & $\Delta q, r$ & -- & -- & امريكا \\
\hline-- & -- & -- & -- & 11 & $\Lambda, 7$ & rru & $\mathrm{V}, \varepsilon$ & -- & -- & استز اليا \\
\hline-- & -- & ir & $\leqslant 1,7$ & -- & -- & -- & -- & -- & -- & اوروجواي \\
\hline$\varepsilon$ & $1, v$ & -- & -- & -- & -- & -- & -- & -- & -- & اسر ائيل \\
\hline rq & 11, & -- & -- & -- & -- & -- & -- & -- & - & زيمبابوى \\
\hline \multirow[t]{2}{*}{$r \cdot r$} & $\Lambda \mu, \tau$ & -- & -- & -- & -- & -- & -- & -- & -- & سو ازيلالد \\
\hline & 1,7 & & -- & & $r, 1$ & & 1,7 & & $\varepsilon, 0$ & 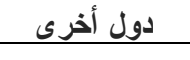 \\
\hline 1.1 & $1 \ldots$ & ro & $1 \ldots$ & $\leqslant 1$ & $1 \ldots$ & 1 & $1 \ldots$ & $(r)$ & $1 \ldots$ & الاجمالى \\
\hline
\end{tabular}

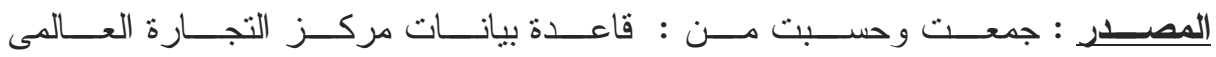

www.comtrade.com

أما بالنسبة للسوق البر ازيلى فتأتى أسبانيا قى مقدمة الدول المتتافسه على تصدير البرتقــال

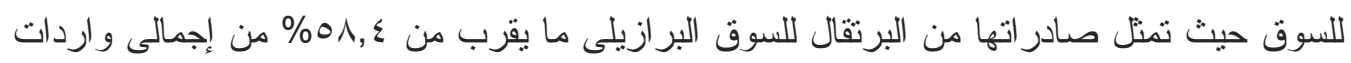

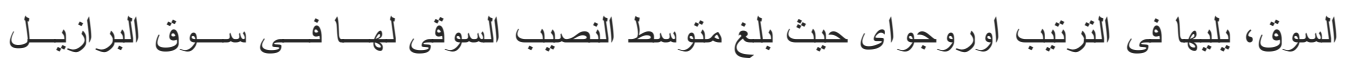

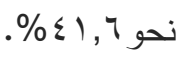
أما بالنسبة لسوق جنوب افريقيا فتأنى سوازيلاند قى مقدمة الدول المتتافسه علــى تصـــير

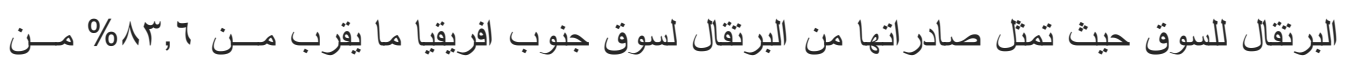




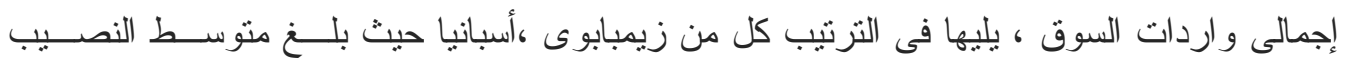

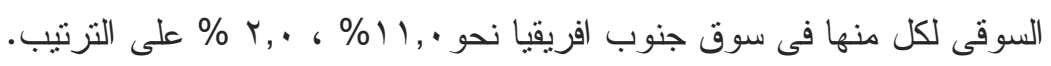

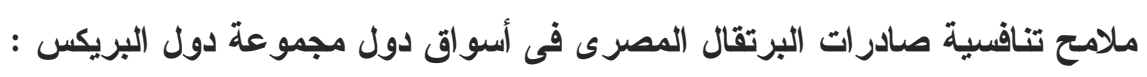

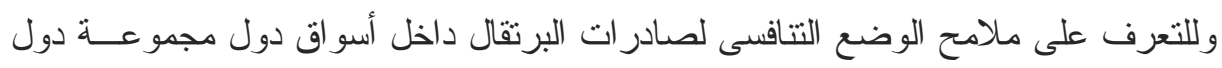

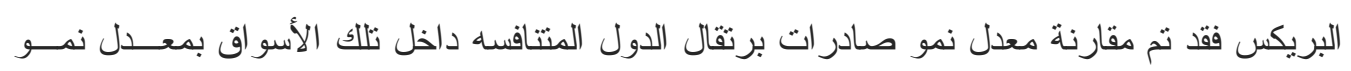

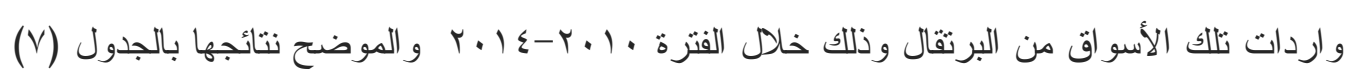
حيث تبين الأتى: أولا روسيا الاتحادية : الاتى:

يعد السوق الروسى من الأسواق التى يتر اجع فيها الطلب على البرتقال حيث تبين أن كميـــة

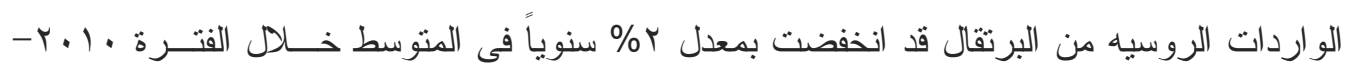

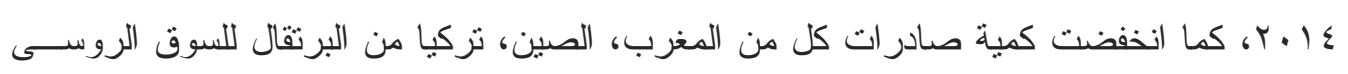

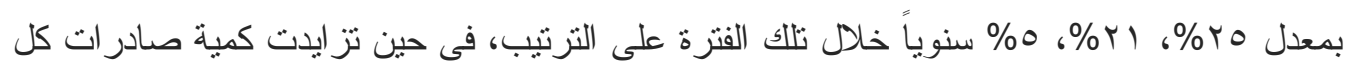

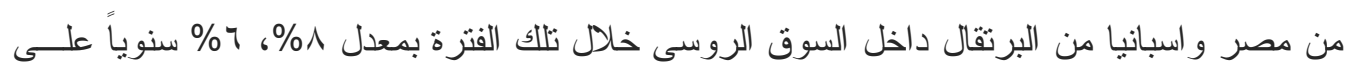

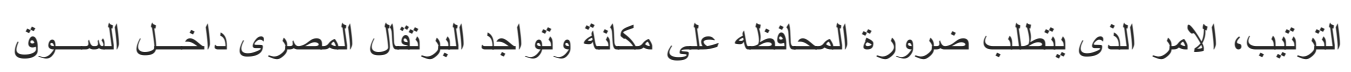

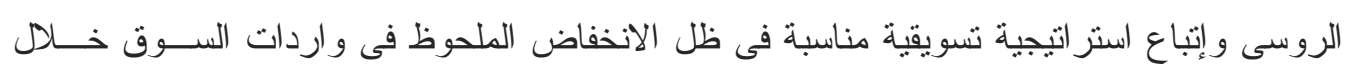

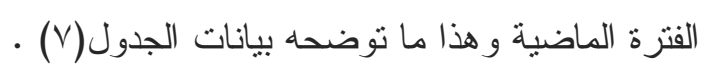
ثانياً الصين :

السوق الصينى من الأسواق التى بيزز ايد فيها الطلب على البرنقال ولكن ببطء حيث تبين أن

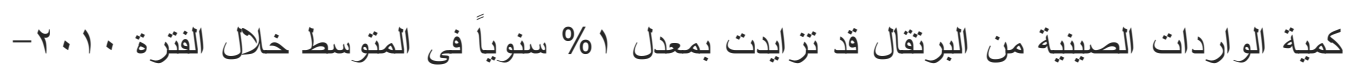

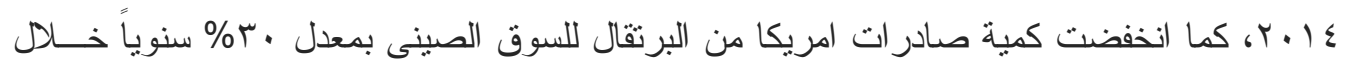

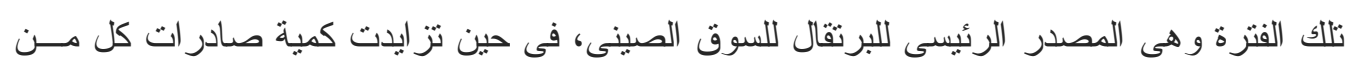

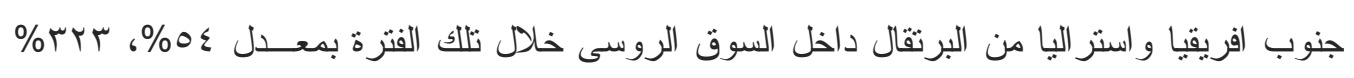

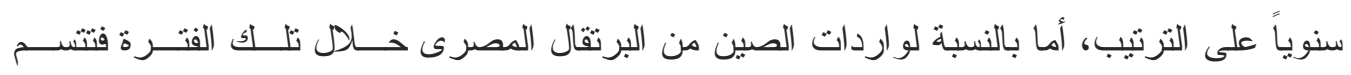
بالتذبذب وعدم الاستقر ار، الامر الذى بيتلب ضرورة إعادة النظر فى استر اتيجية تصدير البرتقـــال

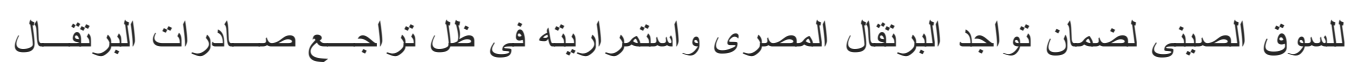

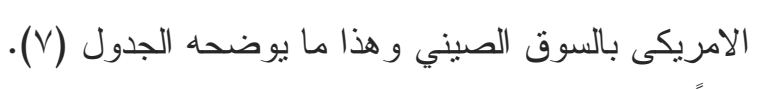
ثالثاً الهند :

بالرغم من صغر حجم سوق واردات الهند من البرثقال نسبيا الا أن معدلات نمــو الســوق

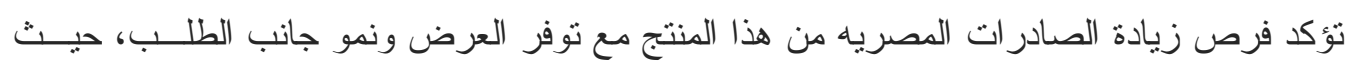

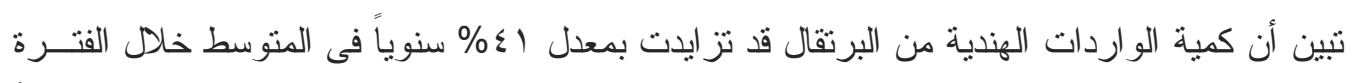

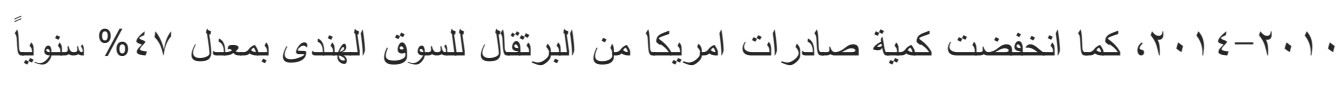

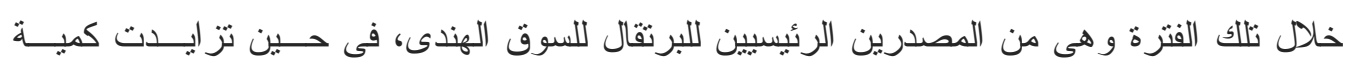

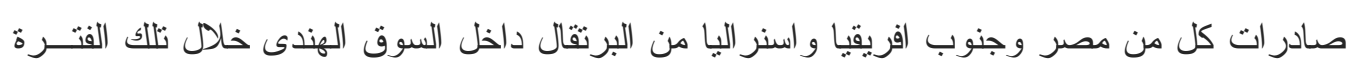




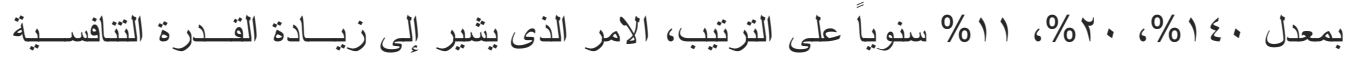

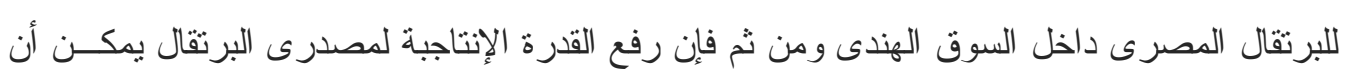

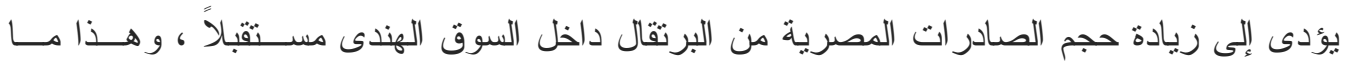

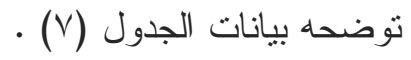
رابعاً البرازيل : بانه

السوق البر ازيلى من الأسواق التى يتز ايد فيها الطلب على البرتقال حيــث تبــين أن كميــة

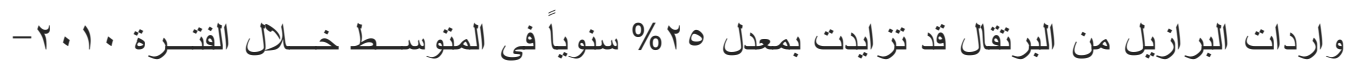

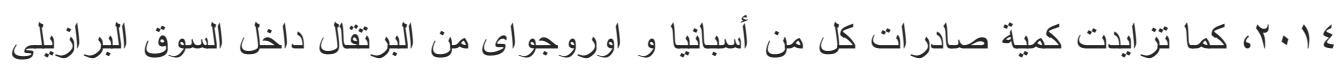

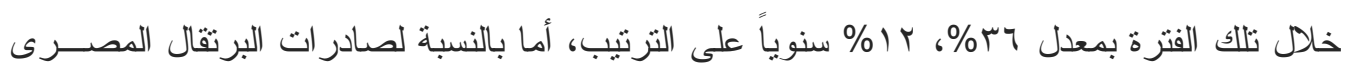

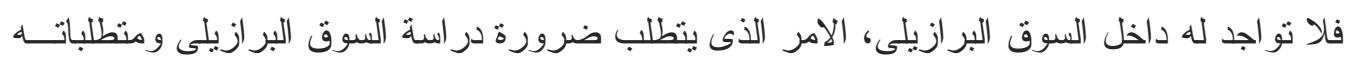

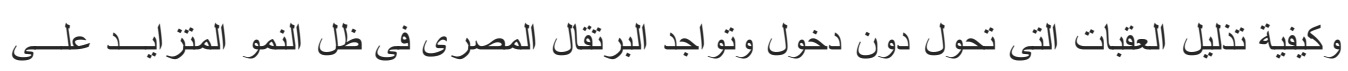

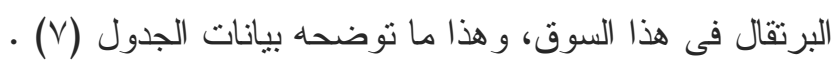

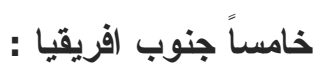

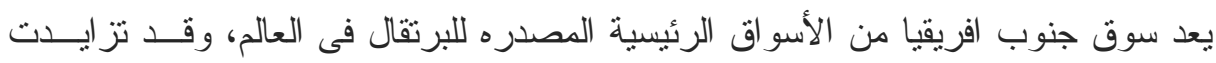

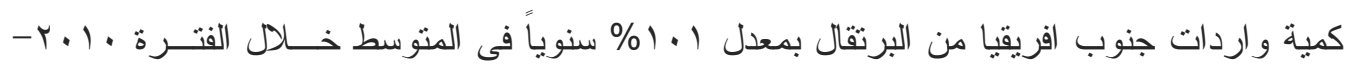

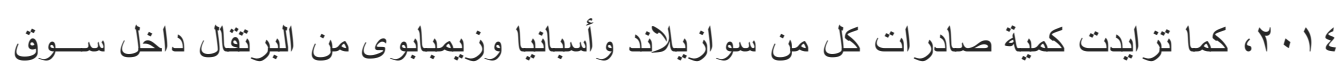

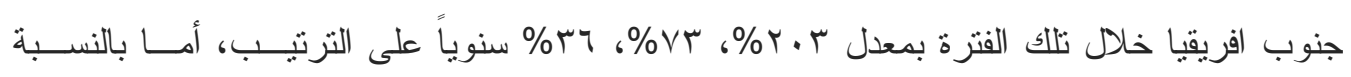

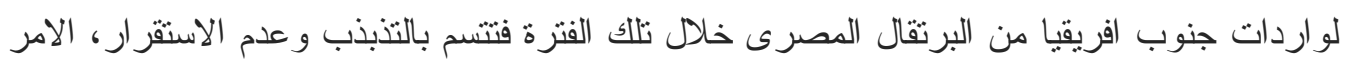

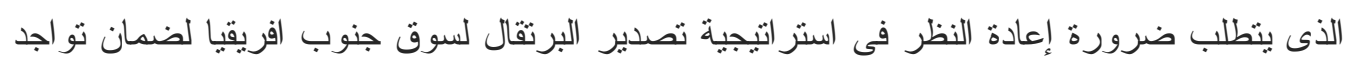

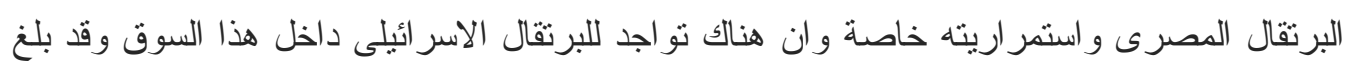

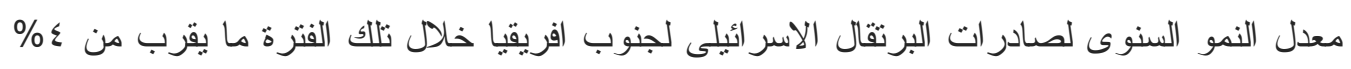

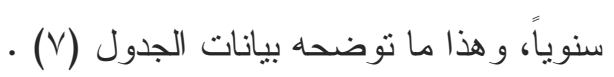

مؤشرات تنافسية صادرات البرتقال المصرى فى أسواق دول مجموعة دول البريكس : وسوف نتتاول فيما يلى بعض المؤشرات التى تؤثز علــى تتافسـية صـــادرات البرتقــال

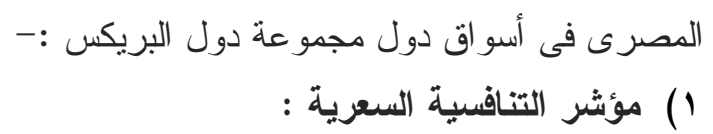

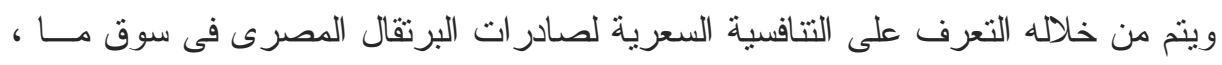
ويتم حسابه بالخطو ات الآتية :

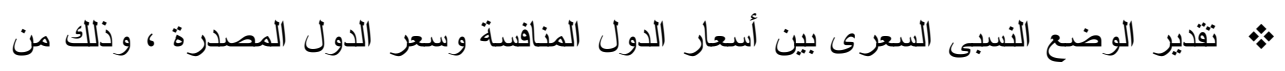

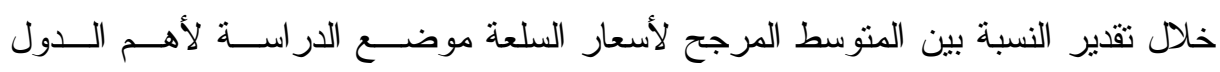

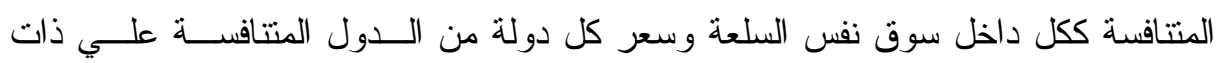
السوق، وذللك بإستخدام المعادلة الأتية: 


$$
\mathbf{P}_{\mathrm{Aj}}=\mathbf{P}_{\mathrm{C}} / \mathbf{P}_{\mathrm{E}}
$$

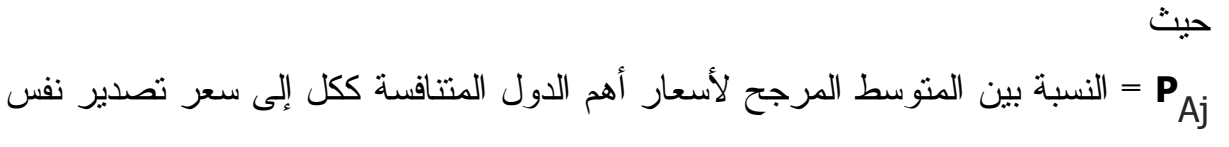

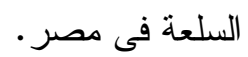
= P المتوسط المرجح لأسعار أهم الدول المتتافسة ككل فى سنة ما. سعر نصدير نفس السلعة فى مصر فى نفس السنه. • ثقدير مؤشر التنافسية السعرية للبرتقال المصرى بإستخدام المعادلة الأتية :

$\mathbf{R}_{\text {aj }} \quad=\frac{}{\mathbf{P}_{\text {Amax }}-\mathbf{P}_{\text {Amin }}}$

Raj : تثير إلى التنافسية السعرية للبرنقال المصرى. : PA ma ، PA min المتوسط المرجح لأسعار أهم الدول المتتافسة ككل إلى سعر تصدير نفس السلعة بكل دولة من الدول المنافسة فى نفس السوق.

وتتحصر قيمة المعادلة بين الصفر و الواحد الصحيح وكلما ارتفعت هذه القيمة دل ذلك علــى

تحسن الوضع التتافسى السعرى لمصر بالنسبة للدول المنافسة لها داخل السوق و العكس صحيح. بدر اسة نتائج الجدول (^) و الذى يوضح منوســـ الأســـار التصــــيرية ومؤشر النتافســية السعرية للبرنقال للدول المنافسة للبرتقال المصرى داخل أسواق تجمع دول البريكس حيث تبين أنه : روسيا الاتحادية :

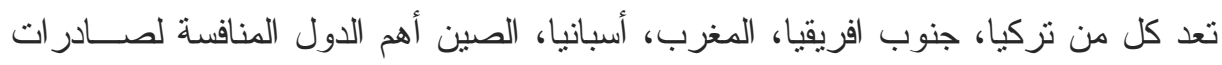
البرتقال المصرى بالسوق الروسى، وبمقارنة متوسط أسعار تصدير البرتقال للدول المتتافسه بالسوق السون

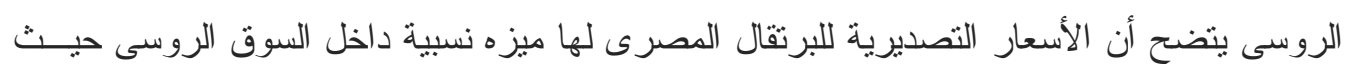

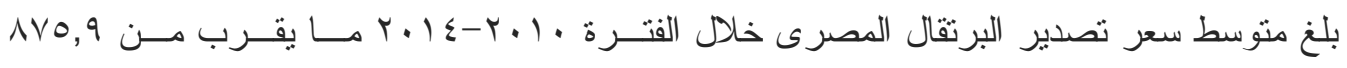
دو لار/طن وهو أقل من المتوسط العام لأسعار واردات السوق الروسى من البرتقال خلال تلك الفترة

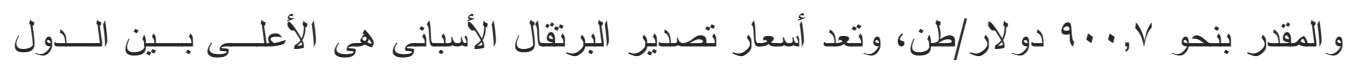

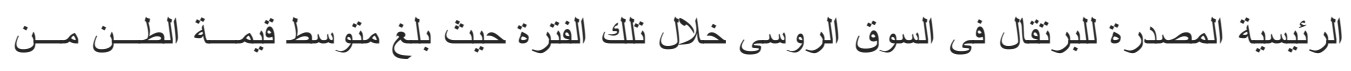

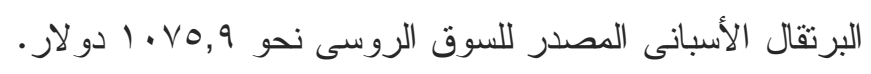

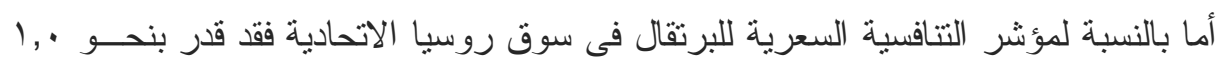

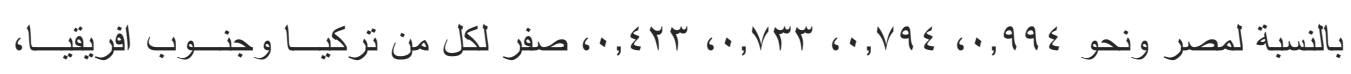

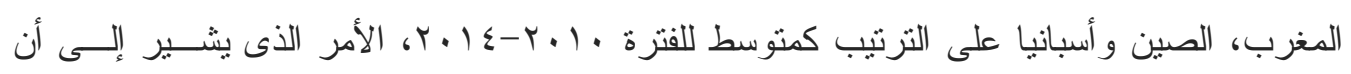

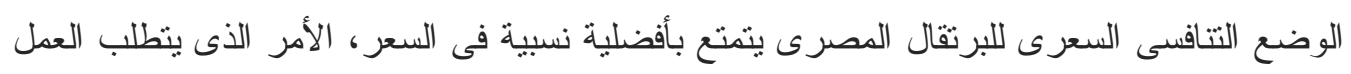
على المحافظة على تلكى الميزة السعرية التى يتمتع بها البرتقال المصرى فيى سوق روسيا الاتحادية . 
تعتبر كل من أمريكا، جنوب افريقيا، استر اليا أهم الدول المنافســة لصــادرات البرتقــال المصرى بالسوق الصينى، وبمقارنة منوسط أسعار تصدير البرتقال للاول المتنافسه بالسوق الصــينى

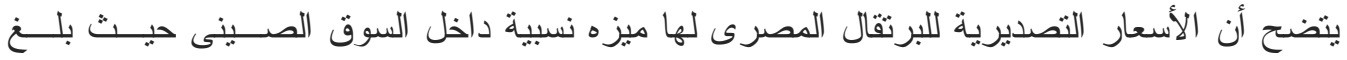

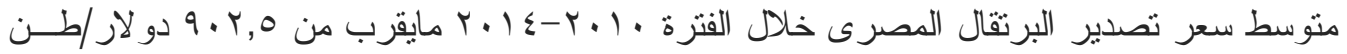

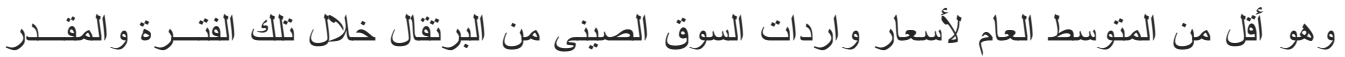

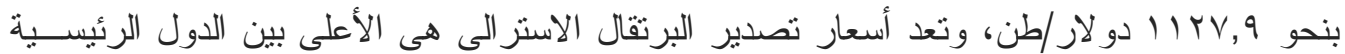
المصدرة للبرتقال فى السوق الصينى خلال تللك الفترة حيث بلغ متوسط قيمة الطــن مــن البرتقــال الاستر الى المصدر للسوق الصينى نحو V,0 10 1 دولار .

أما بالنسبة لمؤشر التتافسية السعرية للبرتقال فى السوق الصينى فقد قدر بنحو ·, بالنسبة

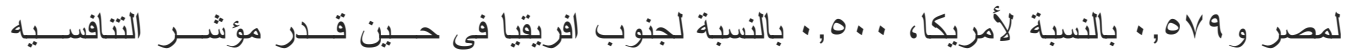

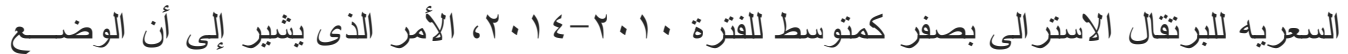

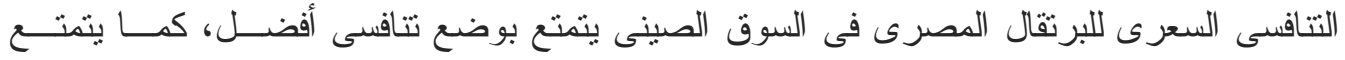

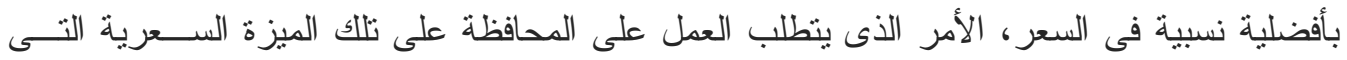
يتمتع بها البرتقال المصرى فى السوق الصينى.

$$
\text { • الهند : }
$$

تعتبر كل من أمريكا، جنوب افريقيا، استر اليا، الصين أهــم الــدول المنافـــة لصـــادر ات

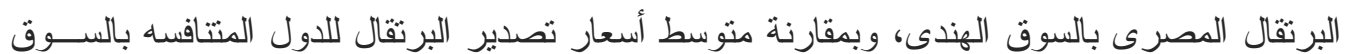

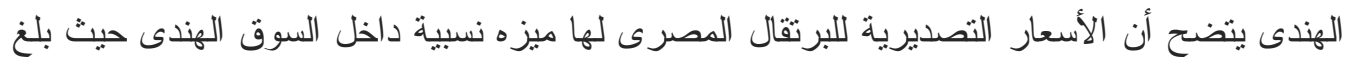

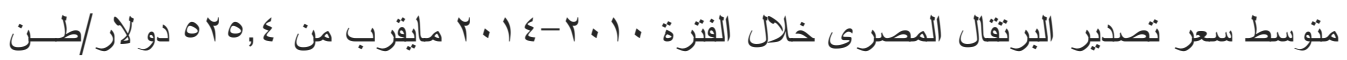

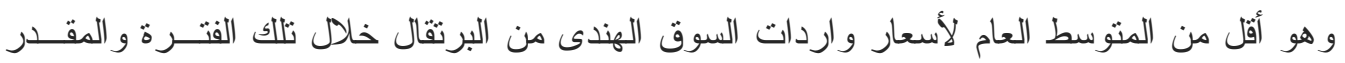

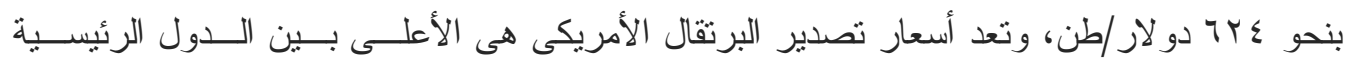

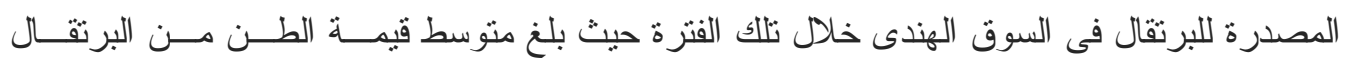

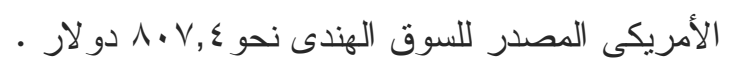

أما بالنسبة لمؤشر التتافسية السعرية للبرتقال فى السوق الهندى فقد قدر بنحو • , البالنسبة

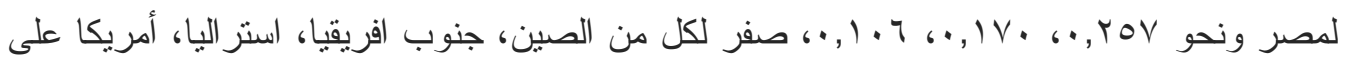

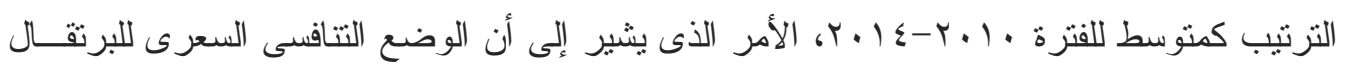

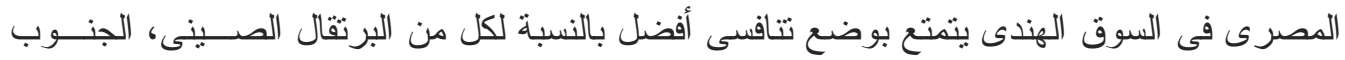

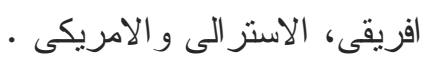


فتنثير البيانات إلى أن واردات السوق من البرتقال تكاد تكون قاصــره علــى اوروجـــواى

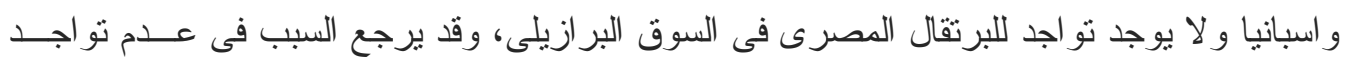

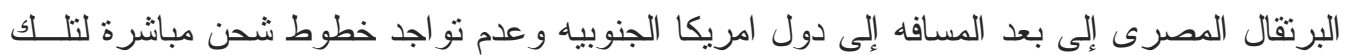

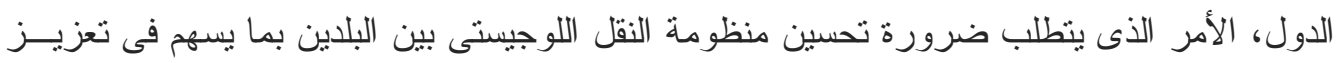

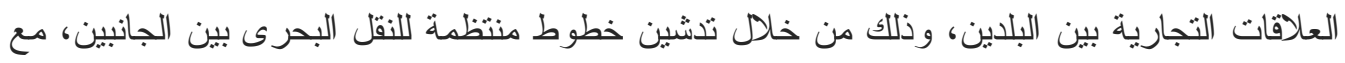

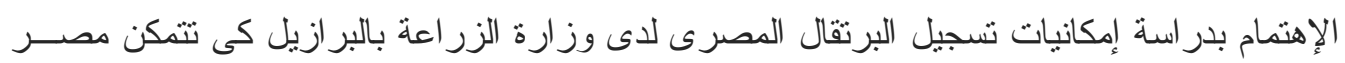
من تصديره للأسو اق البر ازيلية.

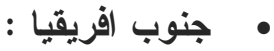

تعد كل من زيمبابوى، سو ازيلاند، اسر ائيل، أسبانيا أهم الدول المنافسة لصادر ات البرتقــال

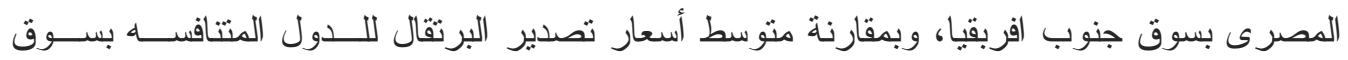

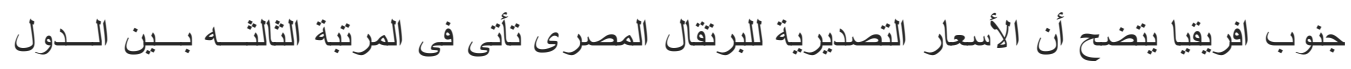

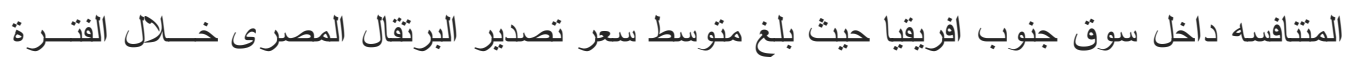

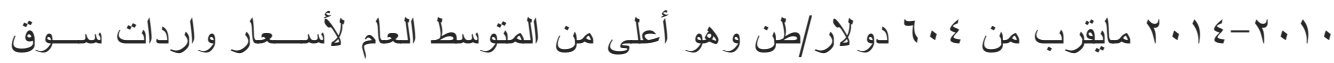

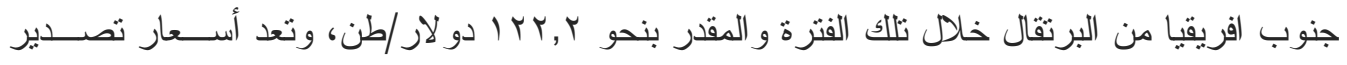

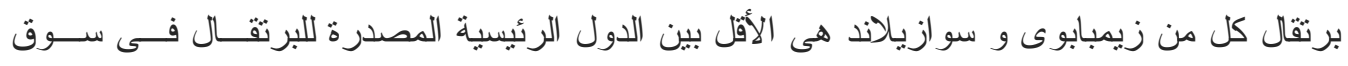
جنوب افريقيا خلال نلك الفترة . أما بالنسبة لمؤشر التتافسية السعرية للبرتقال فى سوق جنوب افريقيا فقد قدر بنحو وب +,.

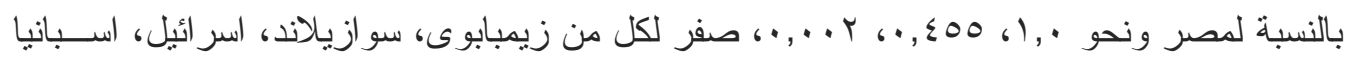

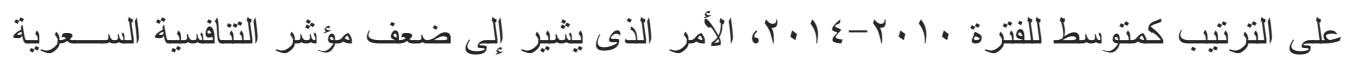

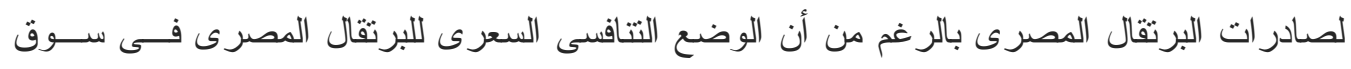

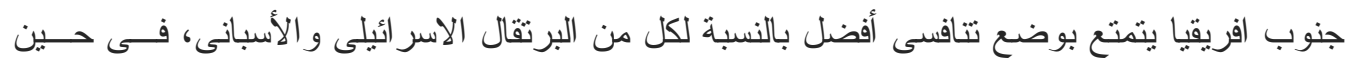

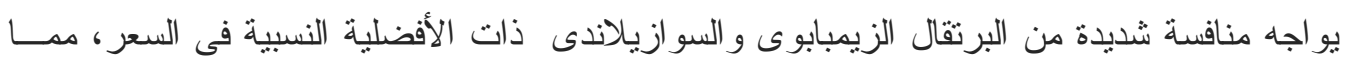

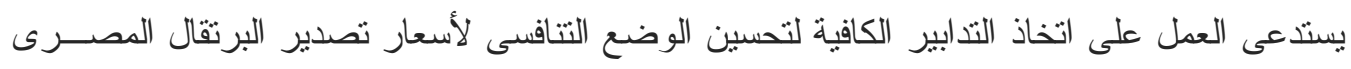

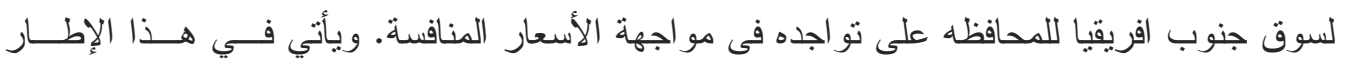
العمل علي خفض بنود تكلفة الطن المصدر من البرنقال. 


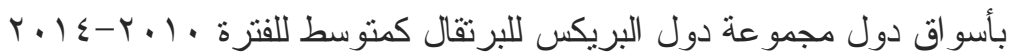

\begin{tabular}{|c|c|c|c|c|c|c|c|c|c|c|}
\hline \multicolumn{2}{|c|}{ جنوب افريقيا } & \multicolumn{2}{|c|}{ البرازيل } & \multicolumn{2}{|c|}{ الهند } & \multicolumn{2}{|c|}{ الصين } & \multicolumn{2}{|c|}{ روسيا الاتحادية } & \multirow[b]{2}{*}{ الالدتنافسة } \\
\hline التنافسية & متوسط & التنافسية & متوسط & التنافسية & متوسط & التنافسية & متوسط & التنافسية & متوسط & \\
\hline .,.ra & ४. \& & -- & -- & $1, \cdot$ & oro, \& & $1,$. & Q.r., & $1, \cdot$ & $\wedge v_{0, q}$ & مصر \\
\hline-- & -- & -- & -- & ., iv. & $v \times q, 9$ &., $0 \ldots$ & $\| r \wedge, \varepsilon$ & . $\vee \vee १ \leqslant$ & $91,, v$ & جنوب \\
\hline-- & -- & - & -- & -- & - & -- & -- & .,११६ & AVY, 9 & تركيا \\
\hline-- & -- & -- & -- & -- & -- & -- & -- & •, Vrr & Qr।,V & المغرب \\
\hline.,$\ldots$ & $9 \leqslant v, 0$ & $\therefore, \ldots$ & $9 \leqslant 1, r$ & -- & -- & -- & -- &.,$\ldots$ & $1 . v_{0,9}$ & اسبانيا \\
\hline-- & -- & -- & -- & . YOV & -- & -- & -- & D & & الصين \\
\hline-- & -- & - & -- &.,$\ldots$ & $\Lambda \cdot v, \varepsilon$ &., $0 \vee 9$ & $1 \cdot \wedge \cdot, \wedge$ & -- & - & امريكا \\
\hline-- & - & - & -- &., 1.4 & VIs, & $\ldots$ & $10.0, v$ & -- & -- & استر اليا \\
\hline-- & -- & $1, \cdot$ & $790, V$ & -- & -- & -- & -- & -- & -- & اوروجوا \\
\hline , , r r & $9 . \&, q$ & -- & -- & -- & -- & -- & -- & -- & -- & اسر ائيل \\
\hline & $94, r$ & -- & -- & -- & -- & -- & -- & -- & -- & سوازيلاد \\
\hline $1,$. & & -- & -- & -- & -- & -- & -- & -- & -- & زيمبابوى \\
\hline & Irr, & & Arq, & & צr & & lirv,q & & $q \ldots, v$ & متوسط \\
\hline
\end{tabular}

المصدر : جمعت وحسبت من : قاعدة بيانات مركز التجارة العالمى WWW.comtrade.com

\section{r بوة التصدير لأهم الدول المنافسة :}

وللتعرف على مدى قدرة الدول المنافسة على تصدير البرنقال فى أســواق دول مجموعــة

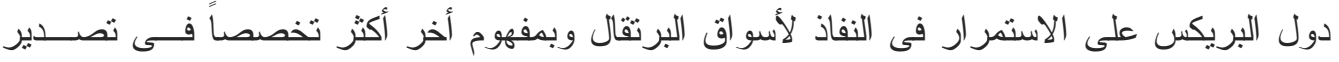

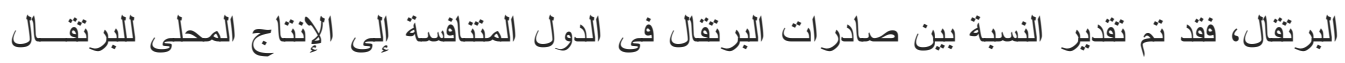
فى تلاك الدول .

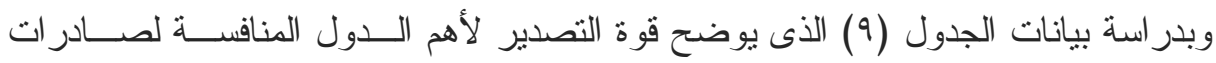

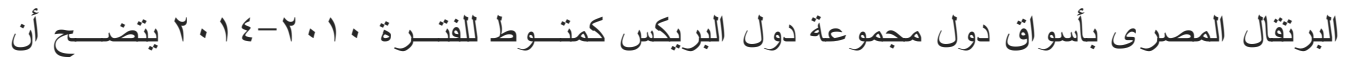

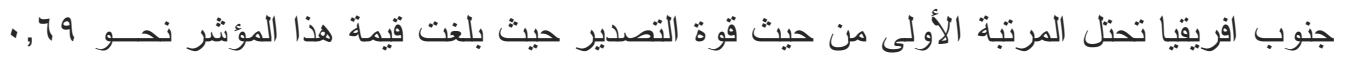

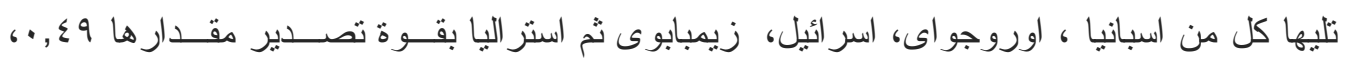

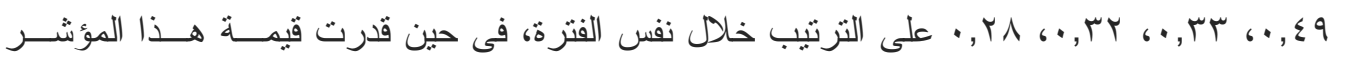
بالنسبة لمصر بنحو 0, · • ويرجع السبب فى ضعف مكانة مصر من حيث قوة التصدير بين الــدول

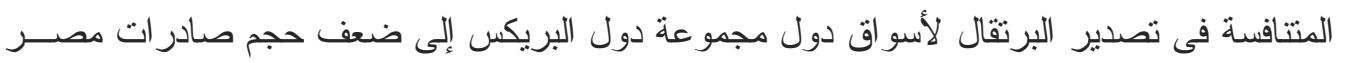

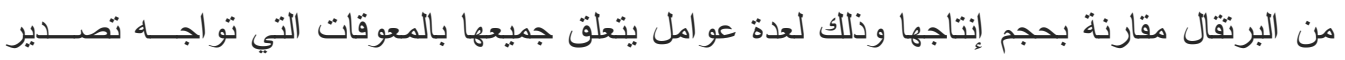

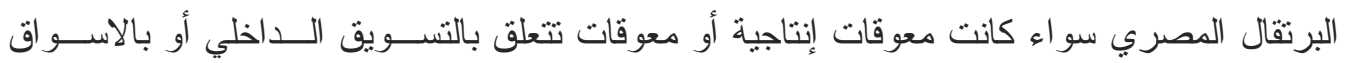
الخارجية أو معوقات تتعلق بالسياسات التصديرية المتبعة. 
جدول (9) : مؤشر قوة التصدير لأهم الدول المنافسة لصادرات البرتقال المصرى بأسواق دول

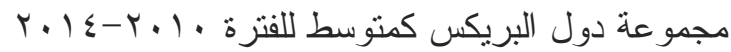

\begin{tabular}{|c|c|c|c|c|c|c|c|c|c|c|c|}
\hline زيمبابوى & اسر ائيل & اوروجواى & استراليا & امريكا & الصين & اسبانيا & المغرب & تركيا & جنوبيا & مصر & المتنافسة \\
\hline , & r, rr & $\cdot, \leqslant 9$ & •, ז^ & $\cdot, v$ & $\cdot, \cdot r$ & ,,$\& 9$ & . YV & $\cdot, 10$ & ., 79 & . Y,o & مؤشر قوة \\
\hline
\end{tabular}

المصدر : جمعت وحسبت من :

قاعدة بيانات مركز التجارة العالمى www.comtrade.com

www.fao.org " " قاعدة بيانات منظمة الأغذيه و الزر اعة " الفارة

\section{موسمية واردات البرتقال بأسواق دول مجموعة دول البريكس :}

مما لاشك فيه أن تحليل موسمية الكميات المستوردة من البرتقال فى اسو اق دول مجموعــة

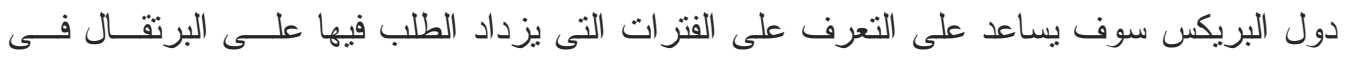

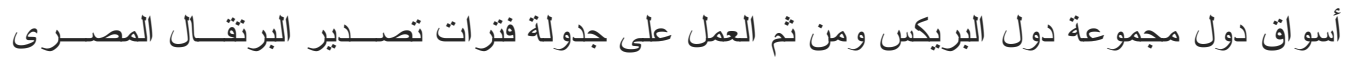

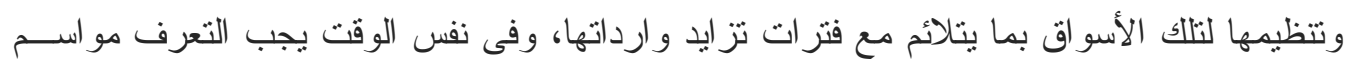

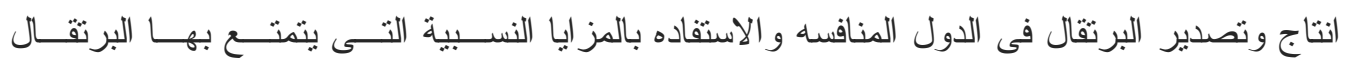

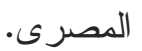
وتجدر الإثارة إلى أن موسم تصدير البرتقال المصرى يبدأ من 10 نوفمبر حتى الأول مـن

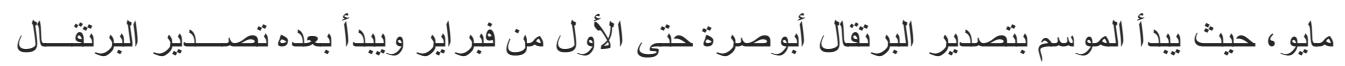

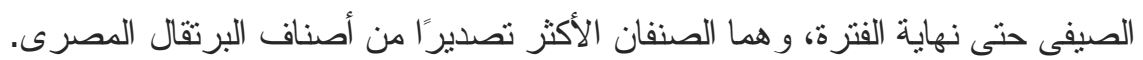
ويشترك مع مصر فى نفس موسم تصدير البرتقال الطازج كل من المغرب و اسبانيا، ولكـن فئن

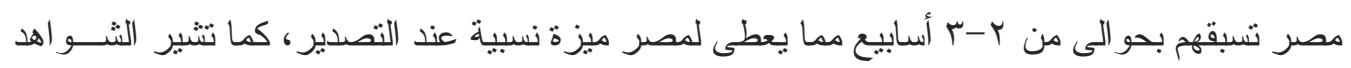

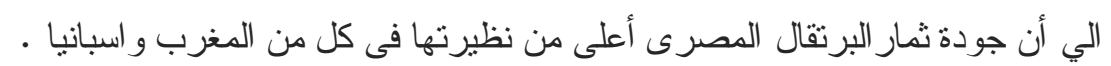

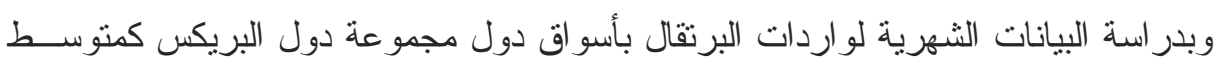

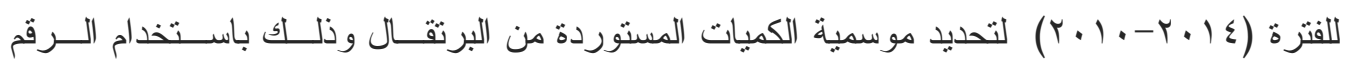
القياسي الموسمي المعدل ، و الموضح نتائجها بالجدول (· · ) يتبين أن الواردات الروسيه من البرنقال

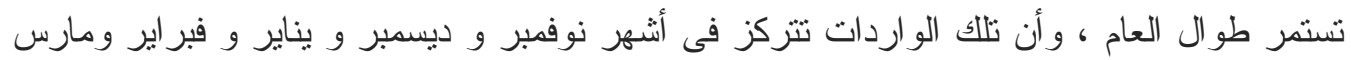

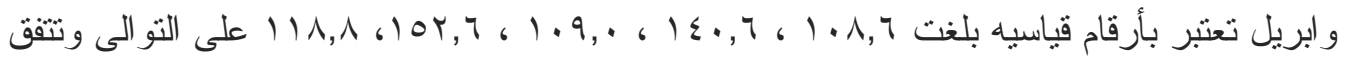

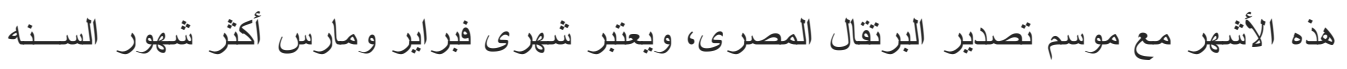

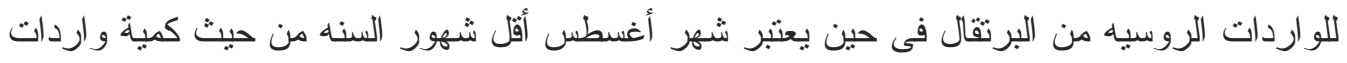

$$
\text { روسيا الاتحاديه من البرتقال. }
$$

أما بالنسبة لواردات السوق البر ازيلى من البرتقال فنجد أنها مستمرة طو ال العام، وأن أثنهر

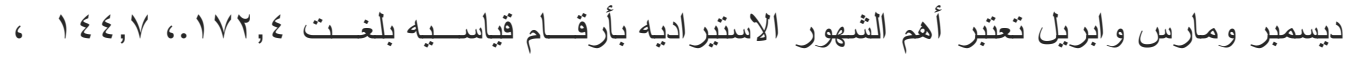


ها مالى 111, .

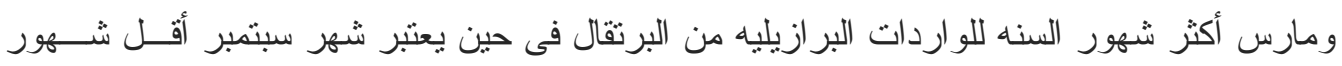

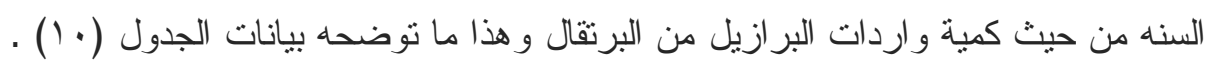

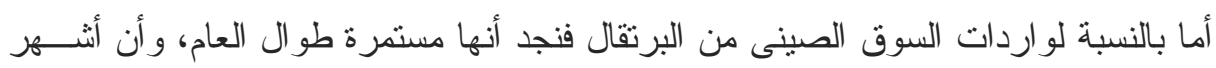

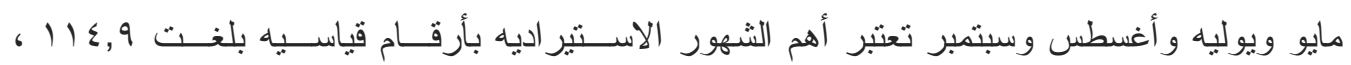

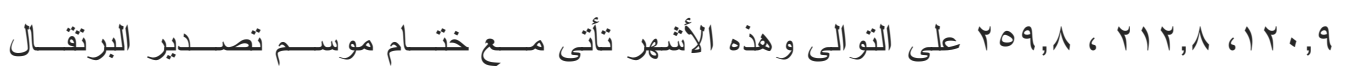

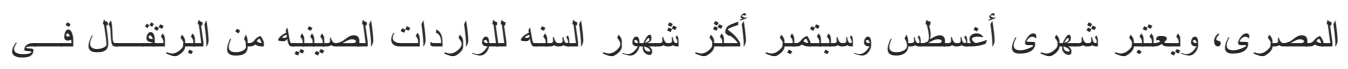

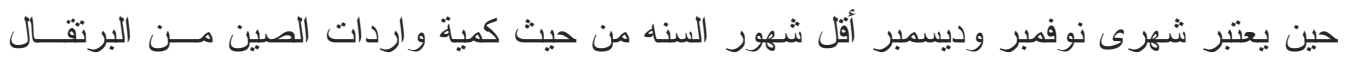

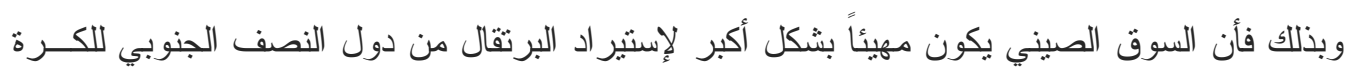

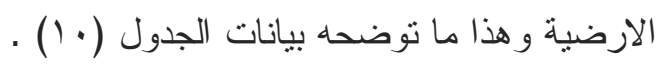
جدول (• (): تطور الرقم القياسى الموسمى لواردات اسو اق دول مجمو عة دول البريكس من البرتقال

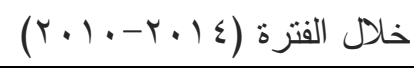

\begin{tabular}{|c|c|c|c|c|c|}
\hline \multicolumn{5}{|c|}{ الرقم القياسى الموسمى } & \multirow{2}{*}{ الشهور } \\
\hline جنوب افريقيا & الهند & الصين & البرازيل & روسيا & \\
\hline 120.4 & 19.6 & 67.0 & 100.7 & 109.0 & بنابر \\
\hline 77.3 & 25.4 & 53.8 & 99.0 & 152.6 & فبر اير \\
\hline 32.5 & 46.5 & 53.4 & 144.7 & 193.1 & مارس \\
\hline 42.2 & 102.3 & 94.4 & 118.0 & 118.8 & (بريل \\
\hline 30.1 & 326.8 & 114.9 & 83.1 & 85.5 & مايو \\
\hline 142.1 & 218.6 & 98.9 & 88.5 & 61.0 & يونيه \\
\hline 240.0 & 189.1 & 120.9 & 76.5 & 46.1 & يوليه \\
\hline 356.2 & 91.1 & 212.8 & 84.5 & 41.1 & |غسطس \\
\hline 81.9 & 82.3 & 259.8 & 61.5 & 55.3 & سبتمبر \\
\hline 56.1 & 62.4 & 85.7 & 73.8 & 88.4 & اكتوبر \\
\hline 9.2 & 27.4 & 10.7 & 97.4 & 108.6 & نوفمبر \\
\hline 12.1 & 8.6 & 27.7 & 172.4 & 140.6 & ديسمبر \\
\hline 100 & 100 & 100 & 100 & 100 & متوسط الثهور \\
\hline
\end{tabular}

المصدر : جمعت وحسبت من : قاعدة بيانات مركز التجارة العالمى www.comtrade.com

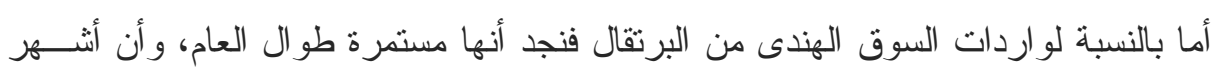

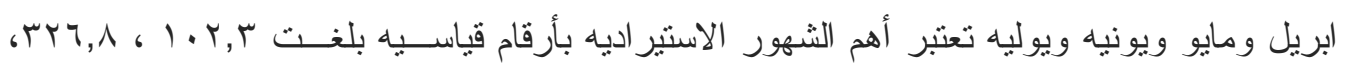

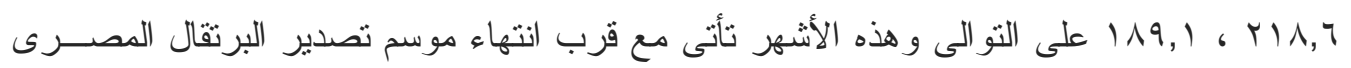

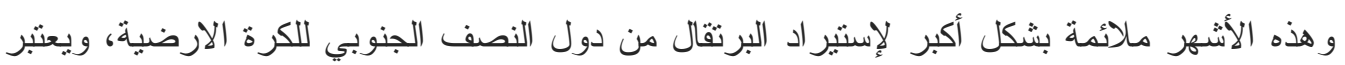

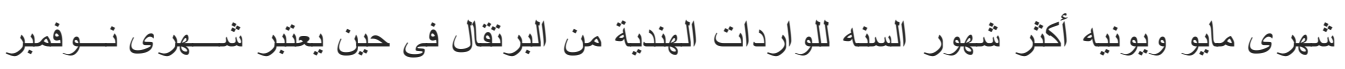

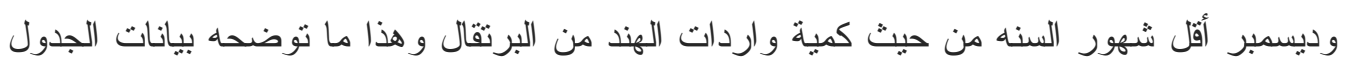

أما بالنسبة لواردات أسواق جنوب افريقيا من البرتقال فنجد أنها مستمرة طو ال العام ، وأن

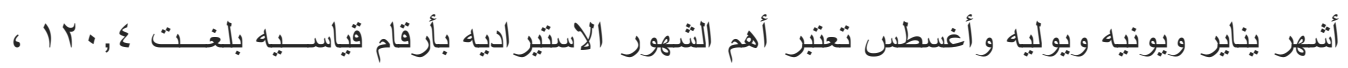




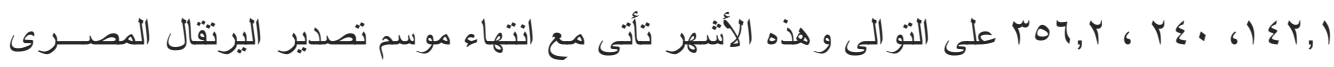

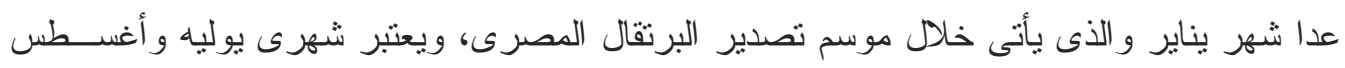

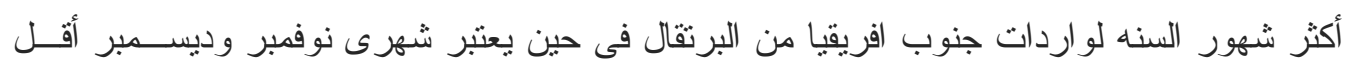

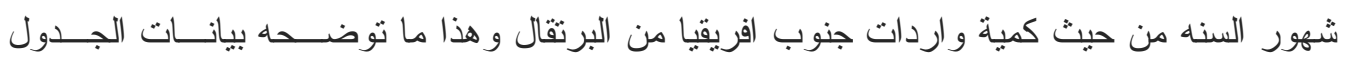

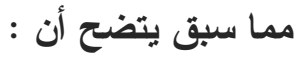

مو اسم استير اد البرتقال بأسو اق مجموعة البريكس بيتفق مع موسم تصدير البرتقال المصرى

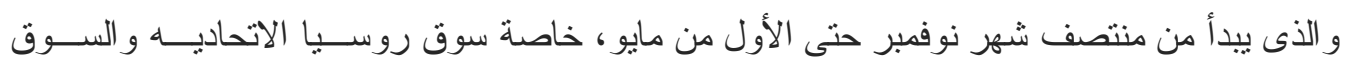

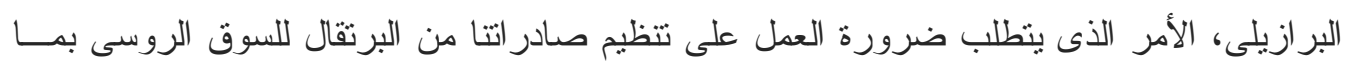

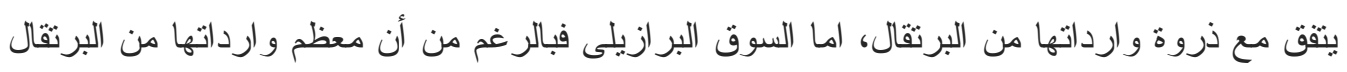

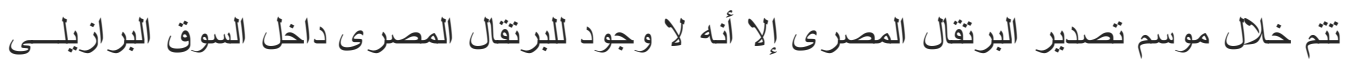

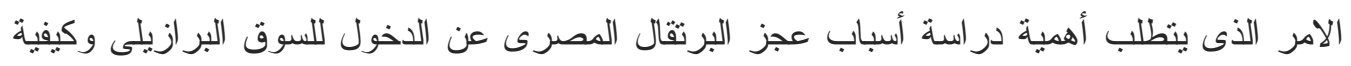

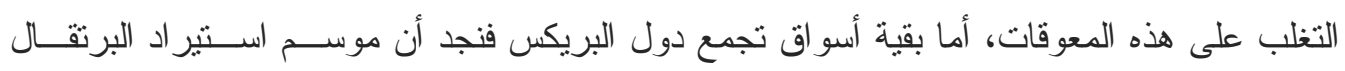

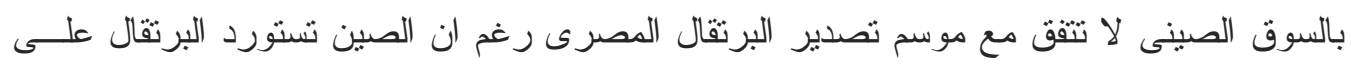

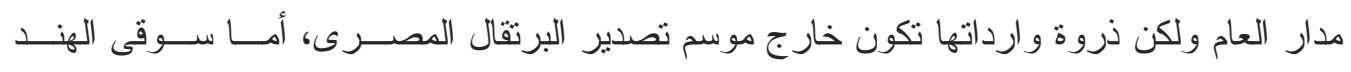

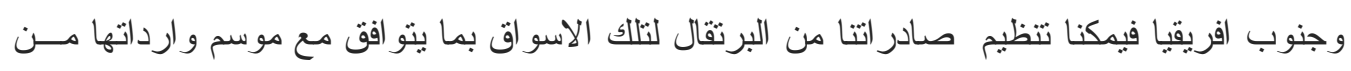
البرتقال و الذى يتفق جزء منه مع موسم تصدير البرنقال المصرى .

أثر اتفاقية مجموعة دول البريكس على صادرات البرتقال المصرى لاول مجموعة دول البريكس :

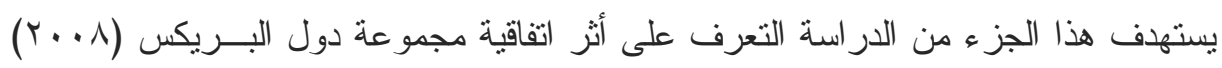

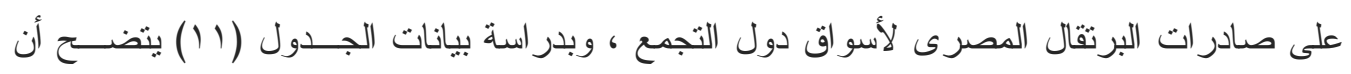

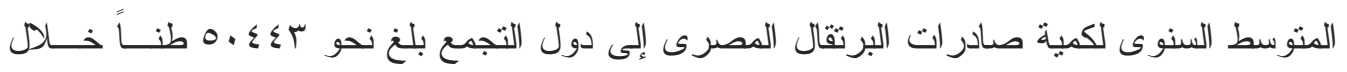

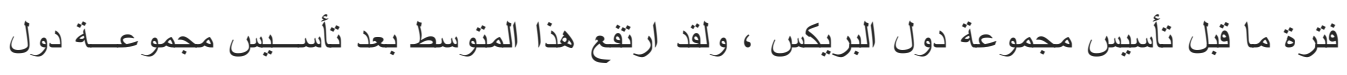

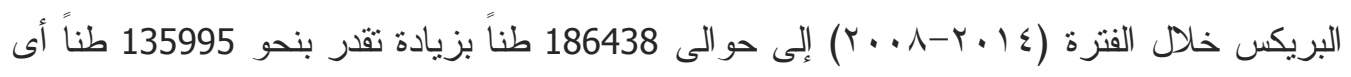

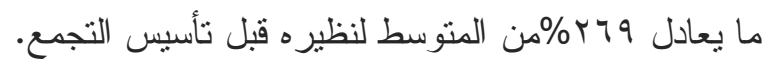




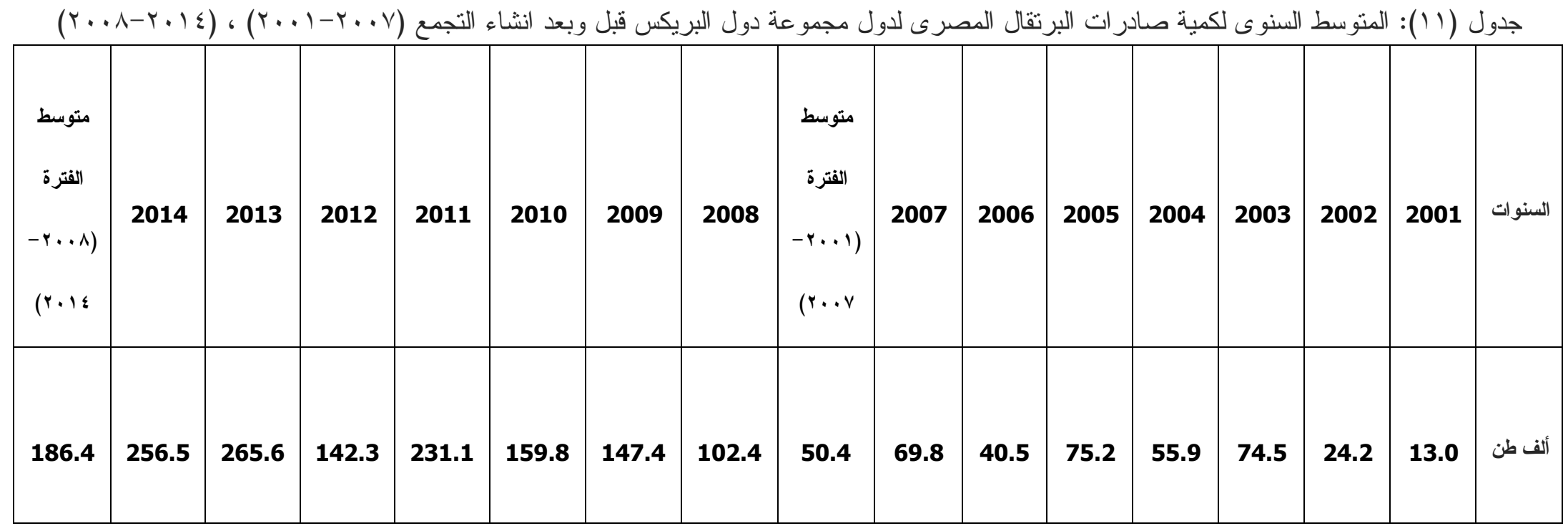

المصدر : جمعت وحسبت من : قاعدة بيانات مركز التجارة العالمى www.comtrade.com 
وبإجر اء اختبار معنوية الفرق بين متوسطى كمية صادرات البرتقال المصرى لأسواق دول

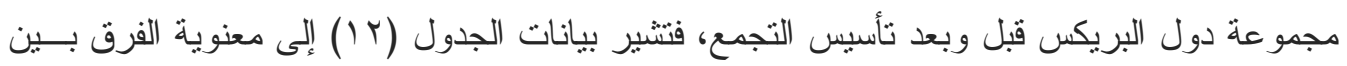

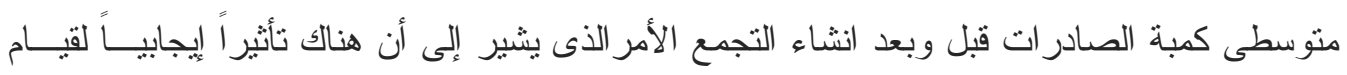

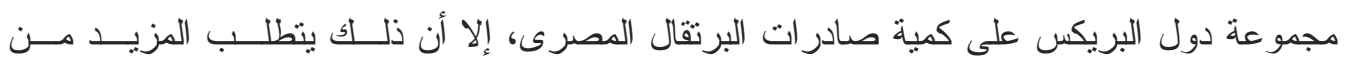

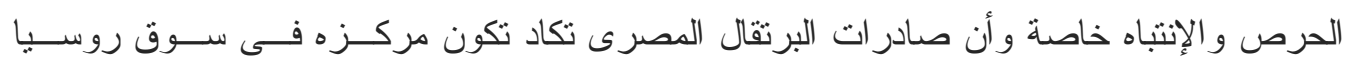

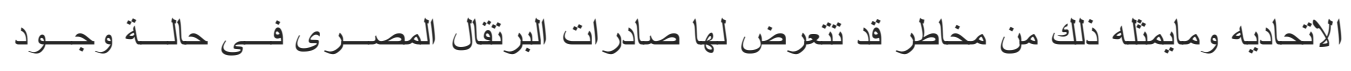

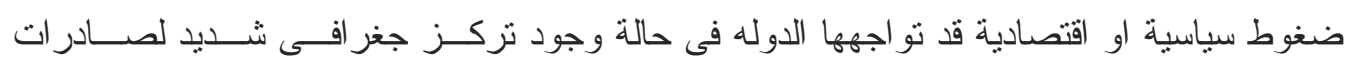
البرتقال، ومن ثم يجب العمل على المحافظة على الأسواق الحالية ودر اسة أسباب عدم تو اجد البرتقال

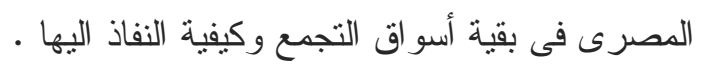
جدول (r (): اختبار معنوية الفرق بين منوسطى صادر ات البرتقال المصرى لدول مجموعة دول

\begin{tabular}{|c|c|c|c|c|}
\hline " ت " المحسوبه & الخطأ & المتوسط & الفترات & البيان \\
\hline \multirow[t]{2}{*}{$0,7 \vee \cdot \varepsilon(-)$} & \multirow[t]{2}{*}{ rraAr,r } & $0 . \leqslant \leqslant r$ & قبل تأسيس التجمع & \multirow[t]{2}{*}{ الكمية بالطن } \\
\hline & & $1 \wedge r \leqslant r \wedge$ & بعد تأسيس التجمع & \\
\hline
\end{tabular}

المصدر : جمعت وحسبت من : بيانات الجدول (r ( ) .

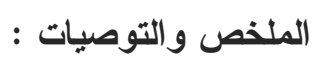

يحتل البرتقال المرنبة الأولى بين حاصلات الفاكهة فى مصر، كما يعـد أحــــ المحاصــيل

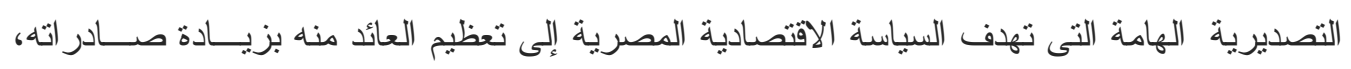

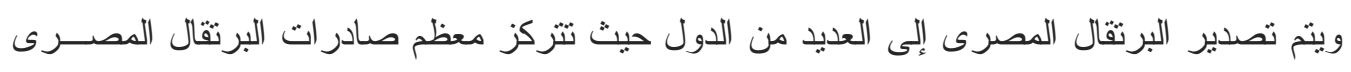

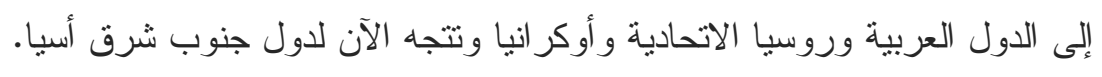

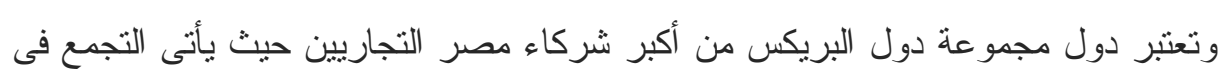

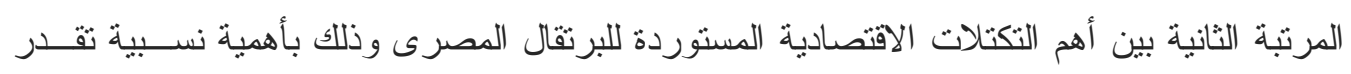

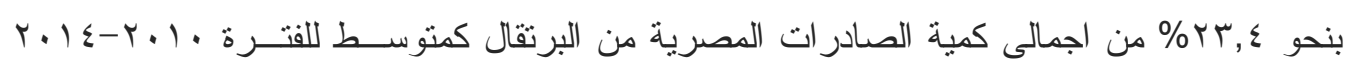

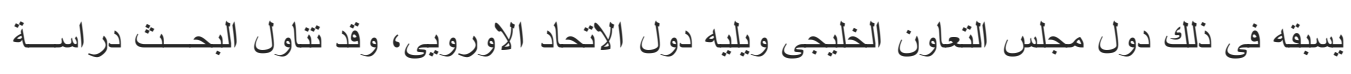

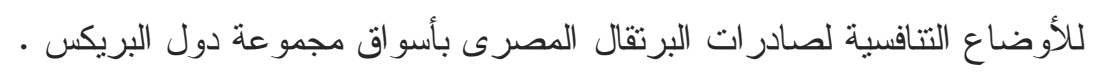

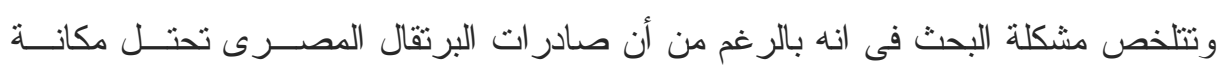

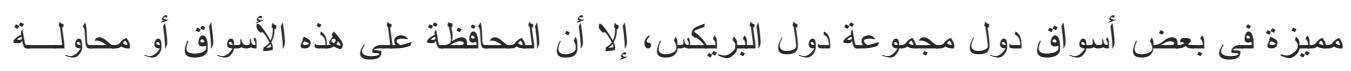

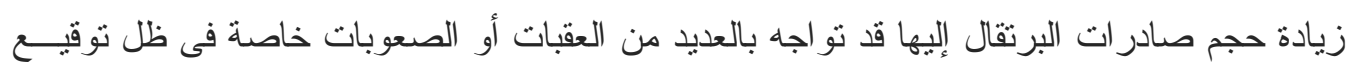

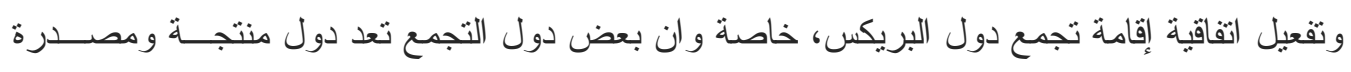

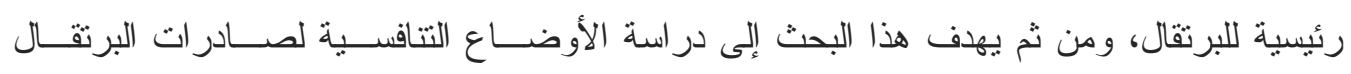

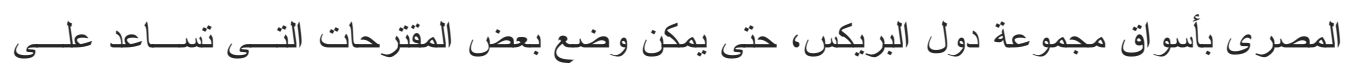


المحافظه على تو اجد البرتقال المصرى ورفع القدرة التتافسية لاستقرار وزيادة الصادرات المصــرية

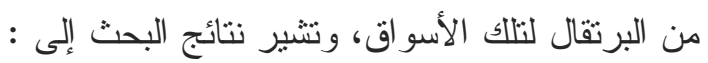

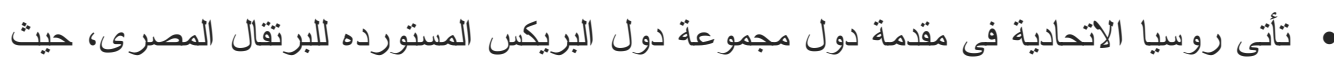

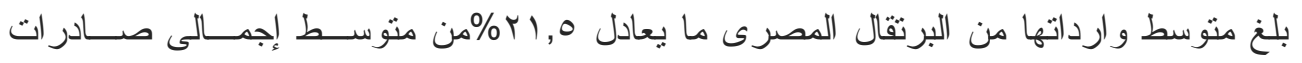

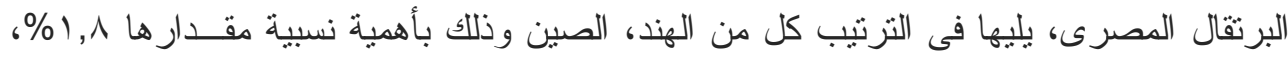

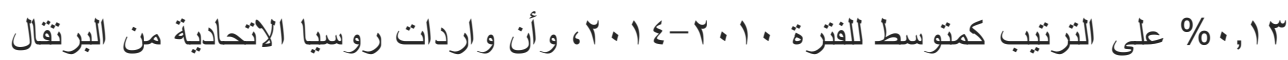
المصرى تمثل نحو $7,19 \%$ (9ن حجم صادرات مصر من البرنقال لدول مجموعة دول البريكس

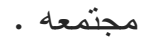

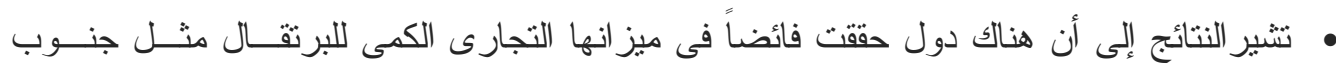

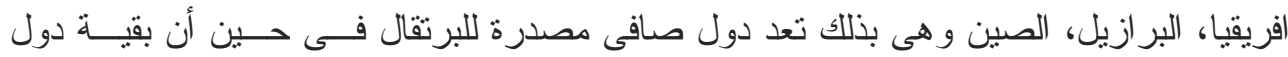

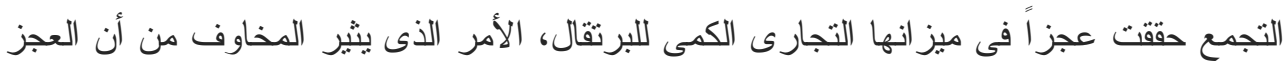

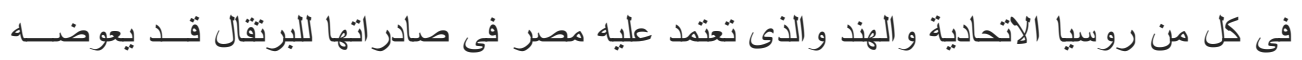
الفائض الذى تحققه بقية دول البريكس خاصة جنوب افريقيا و البرازيل في ظل المعاملة التفضيلية

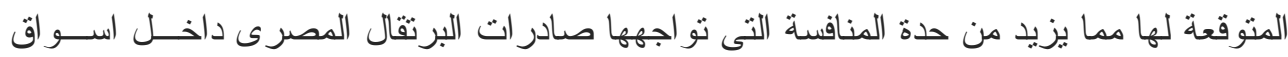

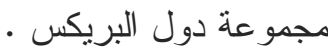
• أنه يمكن تقسيم أسواق دول مجموعة دول البريكس وفقاً لمعدلات نمو واردات نلك الأسواق مــن

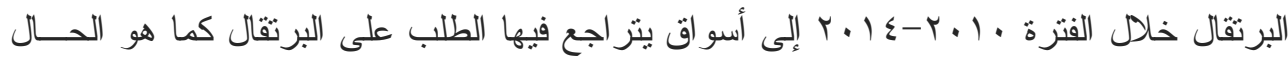

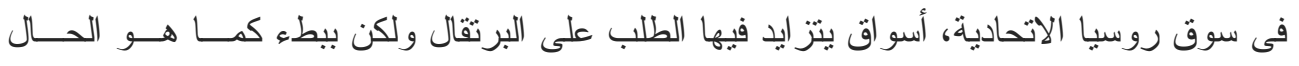
بالسوق الصينى. أما بقية دول التجمع فهى أسو اق يتز ايد فيها الطلب على البرتقال كما هو الحسـال

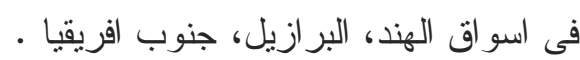
• أن مصر تحتل مكانة مميزة من حيث النصيب السوقى داخل كل من السوق الهندى وسوق روسيا • روسيا

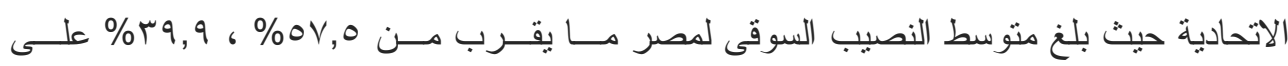
الترتيب من متوسط اجمالى كمية واردات الهند وروسيا الاتحادية من البرتقال، كما تشير النتـــائج

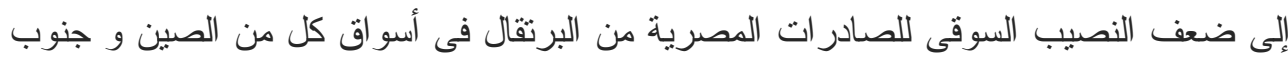

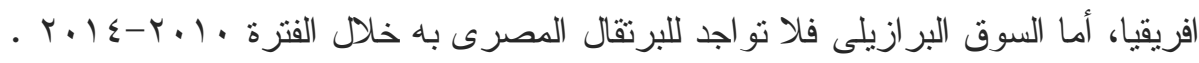

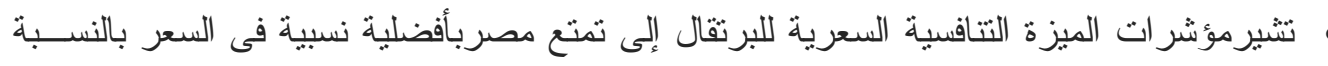

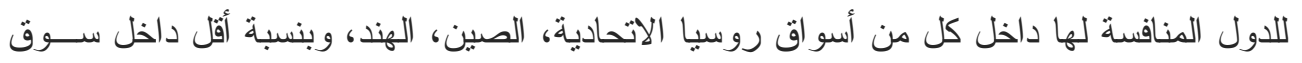

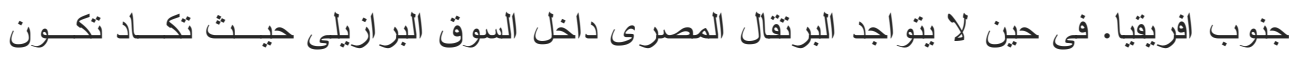

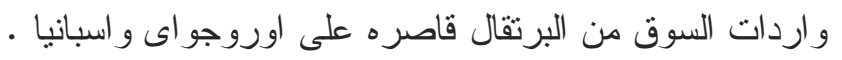

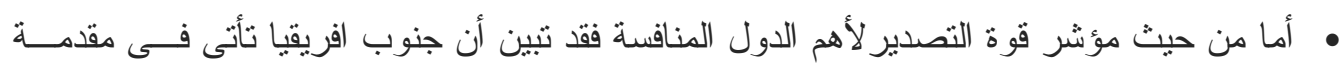

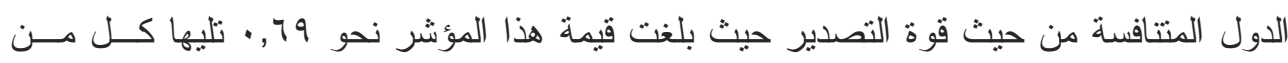

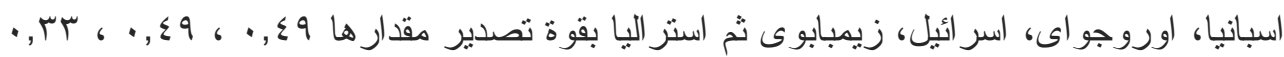




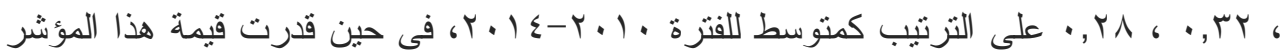
بالنسبة لمصر بنحو مب, •. • أن مو اسم استير اد البرتقال بأسواق دول مجموعة دول البريكس يتفق بعضها مع موسم تصــدير

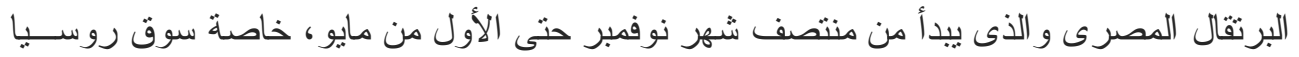

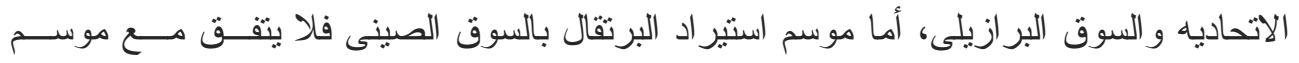

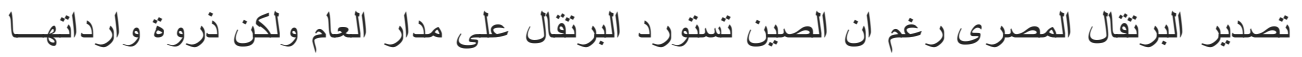

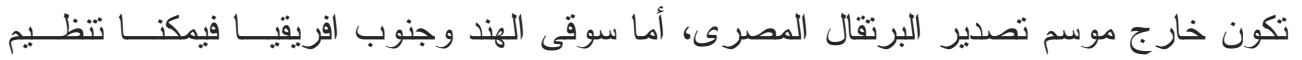

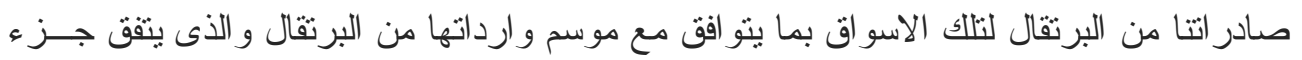
منه مع موسم تصدير البرتقال المصرى. • كما تشير النتائج إلى معنوية الفرق بين متوسطى كمية صادر ات البرتقال المصرى لدول التجمع

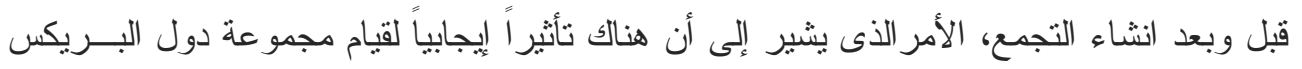

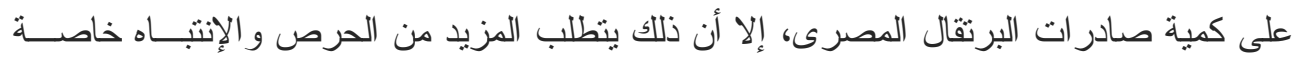
و أن صادر ات البرتقال المصرى تكاد تكون مركزه في سوق روسيا الاتحاديه ومايمثله ذلك مــن مخاطر قد تتعرض لها صادر ات البرنقال المصرى فى حالة وجود ضغوط سياسية او اقتصــادية قد تو اجهها الدوله فى حالة وجود نزكز جغر افى شديد لصادر اتها.

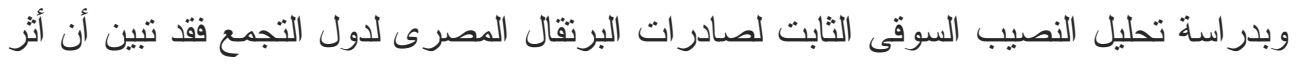

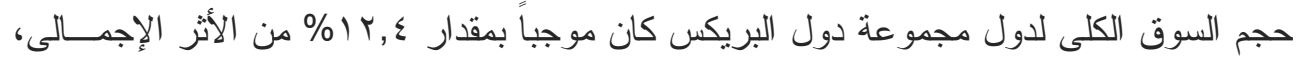

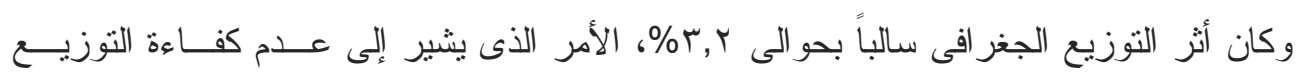

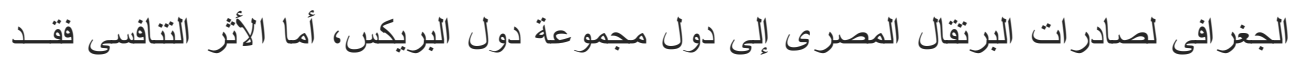

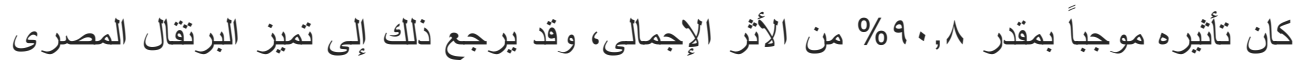
المصدر لدول مجموعة دول البريكس مقارنة بالدول المنافسة.

\section{فى ضوء النتائج التى توصل إليها البحث فإنه يمكن التوصية بالآتى :-}

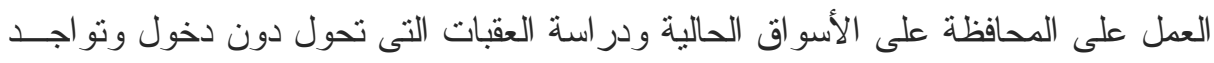
البرتقال المصرى في باقي الأسو اق خاصة فى ظل النمو المنز ايد للطلب فى هذه الأسو اق وذلك مــن

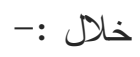

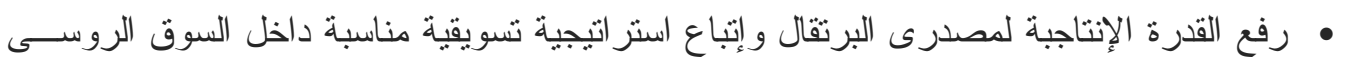

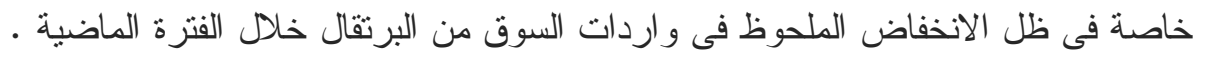
• الحرص على توقيع إتفاق مشترك بين جمعية تتمية وتطوير صــادرات الحاصــلات البســانية

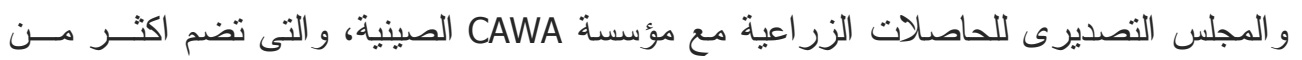

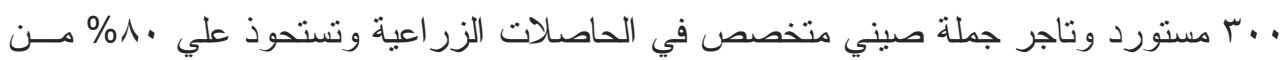

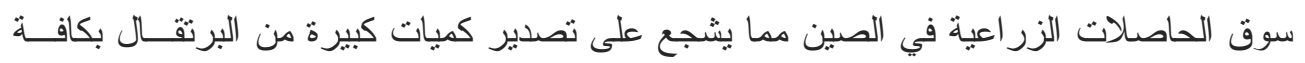
انو اعه الي السوق الصيني. 
• در اسة أتفاقية الميرسكور و العمل على تفعيلها و الموقعة بين مصر و البر ازيل كـأداة مهمـــة مــنـ

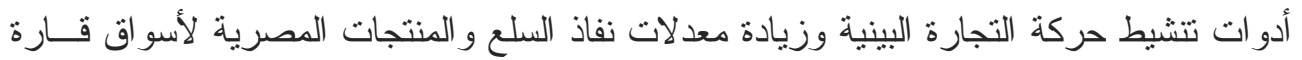
أمريكا الاتينية.

• ضرورة تحسين منظومة النقل اللوجيستى بين البلدين بما يسهم فى تعزيز العلاقات التجارية بـين البلدين، وذلك من خلال تدشين خطوط منتظمة للنقل البحرى بين الجانبين.

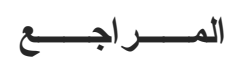

1. الجهاز المركزي للتعبئة العامة و الإحصـاء - المركز القومى للمعلومسـات- بيانــات غيــر

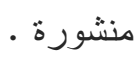

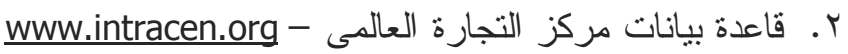
http://www.fao.org بـ منظمة الأغذية و الزر اعة ( الفاو ) -شبكة الإنترنت قاعدة البيانات 